\title{
A Molecular Basis of Analgesic Tolerance to Cannabinoids
}

\author{
Anke Tappe-Theodor, ${ }^{1 \star}$ Nitin Agarwal, ${ }^{1 \star}$ István Katona, ${ }^{2}$ Tiziana Rubino, ${ }^{3}$ Lene Martini, ${ }^{4}$ Jakub Swiercz, ${ }^{1}$ Ken Mackie, ${ }^{5}$ \\ Hannah Monyer, ${ }^{6}$ Daniela Parolaro, ${ }^{3}$ Jennifer Whistler, ${ }^{4}$ Thomas Kuner, ${ }^{7}$ and Rohini Kuner ${ }^{1}$ \\ ${ }^{1}$ Pharmacology Institute, University of Heidelberg, 69120 Heidelberg, Germany, ${ }^{2}$ Institute of Experimental Medicine, Hungarian Academy of Sciences, 1083 \\ Budapest, Hungary, ${ }^{3}$ Department of Structural and Functional Biology, Pharmacology Section and Neuroscience Center, University of Insubria, 21100 \\ Busto Arsizio, Varese, Italy, ${ }^{4}$ Ernest Gallo Clinic and Research Center, University of California, San Francisco, San Francisco, California 94608, ${ }^{5}$ Department \\ of Anesthesiology, University of Washington School of Medicine, Seattle, Washington 98195-6540, ${ }^{6}$ Department of Clinical Neurobiology, Interdisciplinary \\ Center for Neuroscience, 69120 Heidelberg, Germany, and ${ }^{7}$ Max Planck Institute for Medical Research, 69120 Heidelberg, Germany
}

Clinical usage of cannabinoids in chronic pain states is limited by their central side effects and the pharmacodynamic tolerance that sets in after repeated dosage. Analgesic tolerance to cannabinoids in vivo could be caused by agonist-induced downregulation and intracellular trafficking of cannabinoid receptors, but little is known about the molecular mechanisms involved. We show here that the type 1 cannabinoid receptor $\left(\mathrm{CB}_{1}\right)$ interacts physically with G-protein-associated sorting protein 1 (GASP1), a protein that sorts receptors in lysosomal compartments destined for degradation. $\mathrm{CB}_{1}-\mathrm{GASP} 1$ interaction was observed to be required for agonist-induced downregulation of $\mathrm{CB}_{1}$ in spinal neurons ex vivo as well as in vivo. Importantly, uncoupling $\mathrm{CB}_{1}$ from GASP1 in mice in vivo abrogated tolerance toward cannabinoid-induced analgesia. These results suggest that GASP1 is a key regulator of the fate of $\mathrm{CB}_{1}$ after agonist exposure in the nervous system and critically determines analgesic tolerance to cannabinoids.

Key words: cannabinoid receptor 1; receptor trafficking; protein-protein interactions; endocytosis; GASP; spinal nociception

\section{Introduction}

The endocannabinoid system constitutes an important biological defense mechanism against acute and pathological pain (Calignano et al., 1998; Rice, 2001). Neural effects of cannabinoids are primarily mediated by type 1 cannabinoid receptors $\left(\mathrm{CB}_{1}\right)$, which are $\mathrm{G}_{\mathrm{i} / \mathrm{o}}$-coupled $\mathrm{G}$-protein-coupled receptors (GPCRs) (Rice, 2001; Walker and Hohmann, 2005; Mackie, 2006). Cannabinoids effectively attenuate nociceptive hypersensitivity in animal models of chronic pain and have shown promise in preclinical and clinical studies (Rice, 2001; Walker and Hohmann, 2005; Mackie, 2006).

The clinical usage of cannabinoids is limited because of two major reasons. First, cannabinoids cause central side effects, such as sedation, temporary memory impairment, and psychotropic effects (Iverson, 2003; Marsicano and Lutz, 2006). Second, the analgesic efficacy of cannabinoids progressively decreases during repeated usage, a phenomenon referred to as tolerance (De Vry et

\footnotetext{
Received 0ct. 18, 2006; revised Feb. 1, 2007; accepted Feb. 5, 2007.

This work was supported by an Emmy Noether program fellowship and a Klinische Forschergruppe 107 grant from the Deutsches Forschunggemeinschaft (R.K.), Országos Tudományos Kutatási Alapok Grant F046407 and János Bolyai scholarship (I.K.), and National Institutes of Health Grants DA11322 and DA00286 (K.M.). We are grateful to Hans-Joseph Wrede, Radka Zubhakova, and Tatjana Schweizer for excellent technical assistance and Beat Lutz and Giovanni Marsicano for providing $\mathrm{CB}_{7}{ }^{-1-}$ mice for control experiments. The assay for cell surface detection of AP was done in the laboratory of Stefan Offermanns.

*A.T.-T. and N.A. contributed equally to this work.

Correspondence should be addressed to Rohini Kuner, Pharmacology Institute, University of Heidelberg, Im Neuenheimer Feld 366, 69120 Heidelberg, Germany. E-mail: rohini.kuner@pharma.uni-heidelberg.de.

T. Kuner's present address: Department of Anatomy and Cell Biology, University of Heidelberg, Im Neuenheimer Feld 307, 69120 Heidelberg, Germany.

D01:10.1523/JNEUROSCI.5648-06.2007

Copyright $\odot 2007$ Society for Neuroscience $\quad$ 0270-6474/07/274165-13\$15.00/0
}

al., 2004; Martin et al., 2004; Gonzalez et al., 2005; Rubino et al., 2005).

Pharmacodynamic tolerance to drugs is a result of adaptive, use-dependent changes in cellular targets of drugs after longterm or frequent exposure (von Zastrow, 2003). A key determinant of this process is the activation status and the number of receptors expressed at the cell surface. Internalization after agonist exposure constitutes a common feature of numerous GPCRs (Tsao and von Zastrow, 2000). During internalization, some GPCRs rapidly recycle back to the cell membrane, whereas others are sorted into lysosomes and degraded, thereby decreasing functional cell surface receptors (Tsao and von Zastrow, 2000; von Zastrow, 2003). Lysosomal degradation has therefore been postulated to lead to tolerance.

Recently, a protein called G-protein receptor associated sorting protein (GASP) was discovered to mediate the sorting of $\delta$-opioid receptors to lysosomes (Whistler et al., 2002). Subsequent studies revealed that GASP (now called GASP1) is a member of a novel family, consisting of 10 members (GASP-1 to GASP-10) (Simonin et al., 2004), which can physically associate with a variety of GPCRs (Heydorn et al., 2004; Simonin et al., 2004; Bartlett et al., 2005).

So far, several studies have addressed the trafficking of cannabinoid receptors, and the Rab5 GTPase and dynamin have been demonstrated recently to play a role in constitutive endocytosis and axonal targeting of $\mathrm{CB}_{1}$, respectively (Leterrier et al., 2004, 2006; McDonald et al., 2007). However, the molecular mechanisms governing the intracellular fate of cannabinoid receptors during prolonged agonist exposure remain unclear. The intracellular C-terminal tail of $\mathrm{CB}_{1}$ has been identified as a region critical in agonist-induced internalization (Hsieh et al., 1999; Jin et al., 
1999) and could serve as an important avenue for intracellular protein-protein interactions.

We show here that GASP1 interacts with $\mathrm{CB}_{1}$ in the nervous system in which it mediates the sorting of $\mathrm{CB}_{1}$ into lysosomal compartments during protracted agonist exposure. Disruption of the $\mathrm{CB}_{1}-\mathrm{GASP} 1$ interaction via a dominant-negative mutant version of GASP reduces agonist-induced downregulation of $\mathrm{CB}_{1}$ in spinal neurons in culture as well as in vivo. Importantly, the $\mathrm{CB}_{1}-\mathrm{GASP} 1$ interaction is required for analgesic tolerance to cannabinoids. Thus, this study provides the first direct link between molecular mechanisms underlying $\mathrm{CB}_{1}$ receptor trafficking and analgesic tolerance to cannabinoids in vivo.

\section{Materials and Methods}

Plasmids and constructs. The constructs expressing N-terminally hemagglutinin (HA)-tagged human $\mathrm{CB}_{1} \mathrm{cDNA}$ as well as N-terminally HAtagged V460Z (Z: stop codon) and V464Z mutants of $\mathrm{CB}_{1}$ have been described previously (Hsieh et al., 1999). Similarly, constructs expressing green fluorescent protein (GFP) N-terminally in frame with the second codon of human GASP (GFP-GASP) or with the C-terminal 467 amino acids of GASP (GFP-cGASP) and N-terminally HA-tagged cGASP have been described previously (Whistler et al., 2002).

Generation of a stable cell line expressing enhanced $G F P-C B_{1}$. Coding sequence of the $\mathrm{CB}_{1}$ receptor was amplified by reverse transcription-PCR from mouse brain. To avoid potential removal of the enhanced GFP (EGFP) tag from the $\mathrm{N}$ terminus at any unidentified signal peptide cleavage site, the first $25 \mathrm{~N}$-terminal amino acids were excluded from the amplicon. The remaining fragment was cloned in frame behind EGFP, and the fusion construct was sequenced to confirm lack of mutations. Human embryonic kidney 293 (HEK293) cells were maintained according to routine protocols, and $10 \mu \mathrm{g}$ of the plasmid was transfected using calcium chloride ( $2 \mathrm{M})$. Drug-resistant colonies were selected using G418 $(200 \mu \mathrm{g} / \mathrm{ml})$ after $12 \mathrm{~d}$ of treatment, and clones expressing EGFP-CB ${ }_{1}$ at low to moderate levels were propagated further. These clones were picked up and propagated for experimental analysis.

Immunoprecipitation and Western blot analysis. HEK293 cells were scraped and lysed in $500 \mu \mathrm{l}$ of TNE buffer (10 mM Tris, pH 7.5, $0.5 \mathrm{M}$ $\mathrm{NaCl}, 5 \mathrm{~mm}$ EDTA, and $0.1 \%$ Triton X-100). with protease inhibitors $48 \mathrm{~h}$ after calcium phosphate transfection of the indicated constructs. Lysis proceeded for $20 \mathrm{~min}$ at $4^{\circ} \mathrm{C}$, and lysates were then centrifuged for $10 \mathrm{~min}$ at 13,000 rpm in ice-cold tabletop centrifuge. Cleared lysate was then incubated with the indicated antibody. Rabbit anti- $\mathrm{CB}_{1}$ (Cayman Chemical, Ann Arbor, MI), rat anti-HA (Roche, Basal, Switzerland), and rabbit anti-GFP (Chemicon, Temecula, CA) antibodies were used. The antibody-antigen complexes were isolated by binding to $30 \mu \mathrm{l}$ of protein A/G Sepharose beads for $3-4 \mathrm{~h}$ at $4^{\circ} \mathrm{C}$. Beads were then pelleted at 10,000 $\mathrm{rpm}$ for $30-40 \mathrm{~s}$ at $4^{\circ} \mathrm{C}$ and washed four times with ice cold TNE buffer with protease inhibitors. Precipitated proteins were then boiled in SDS sample buffer for $3 \mathrm{~min}$ at $95^{\circ} \mathrm{C}$ and analyzed on 10\% SDS-PAGE gels. Goat anti-rabbit HRP and goat anti-rat HRP antibodies were used for Western blotting following standard protocols. For coimmunoprecipitation from cultured spinal neurons, neurons were pooled from 12-14 $\times$ $10 \mathrm{~cm}$ plates in total volume of $1.5 \mathrm{ml}$ of TNE lysis buffer with protease inhibitors and processed further as described for HEK293 cells.

Immunoprecipitation on rat brain lysates. Brains from adult Wistar rats were dissected, washed with PBS, and homogenized in IPB buffer $(0.1 \%$ Triton X-100, $150 \mathrm{~mm} \mathrm{NaCl}, 25 \mathrm{~mm} \mathrm{KCl,} 10 \mathrm{~mm}$ Tris-HCl, pH 7.4, and 1 mм $\mathrm{CaCl}_{2}$ ) containing Complete, Mini, and EDTA-free Protease inhibitor tablets (Roche) and centrifuged at $1500 \mathrm{rpm}$ for $15 \mathrm{~min}$ at $4^{\circ} \mathrm{C}$. Supernatant was centrifuged at $60,000 \mathrm{rpm}$ for $20 \mathrm{~min}$. The pellet was resuspended in IPB buffer containing $1 \%$ Triton X-100 and protease inhibitors and preincubated for $2 \mathrm{~h}$ at $4^{\circ} \mathrm{C}$ with protein A/G Plus Sepharose beads (Santa Cruz Biotechnology, Santa Cruz, CA). Beads were removed by centrifugation, and the supernatant was incubated with the $\mathrm{CB}_{1}$ antibody (1:200; Chemicon) or GFP antibody (1:1000; Chemicon) overnight, followed by an additional $2 \mathrm{~h}$ incubation with protein $\mathrm{A} / \mathrm{G}$ Plus Sepharose beads. Beads were washed three times with IPB buffer containing $1 \%$ Triton X-100. Subsequently, sucrose cushioning was per- formed twice by adding IPB buffer and $1 \mathrm{~m}$ sucrose to the bottom of the vial. Beads were next washed twice with $1 \%$ Triton X-100/IPB and twice with $10 \mathrm{~mm}$ Tris HCl. Beads were then incubated with PNGase F for $1 \mathrm{~h}$ at $37^{\circ} \mathrm{C}$ and $\mathrm{CB}_{1}$ receptor blocking peptide (Cayman Chemical). Beads were removed by centrifugation, and the supernatant was boiled for 5 min with $4 \times$ SDS sample buffer $(0.03 \mathrm{ml} ; 4 \times$ SDS sample buffer: $286 \mathrm{~mm}$ Tris-HCl, pH 6.8, 5.7\% SDS, 10 mm EDTA, $28 \%$ glycerol, $3.5 \mathrm{mg} / \mathrm{ml}$ bromophenol blue, and $4.7 \mathrm{mg} / \mathrm{ml} \beta$-mercaptoethanol) and loaded on $10 \%$ SDS-polyacrylamide gel. Blots were divided in upper and lower parts and hybridized with anti-GASP antibody (1:1000) (Bartlett et al., $2005)$ or $\mathrm{CB}_{1}$ antibody (1:1000; Chemicon) in $8 \%$ blocking dry milk using anti-rabbit HRP secondary antibody (1:4000) in $8 \%$ blocking dry milk.

Analysis of $C B_{1}$ trafficking in HEK293 cells. HEK293 cells stably expressing GFP- $\mathrm{CB}_{1}$ were cultured with G418 in complete DMEM on poly-L-lysine-coated glass coverslips. In some experiments, cells were transfected using Lipofectamine. At $40 \mathrm{~h}$ after transfection, cells were incubated with cycloheximide $(40 \mu \mathrm{M})$ in DMEM without serum for $1 \mathrm{~h}$ at $37^{\circ} \mathrm{C}$. WIN 55,212-2 [R-(+)-(2,3-dihydro-5-methyl-3-[(4-morpholinyl) methyl]pyrrolo[1,2,3-de]-1,4- benzoxazin-6-yl)(1-naphthalenyl) methanone monomethanesulfonate] (WIN) (100 nM) or vehicle was added in DMEM, and cells were incubated for varying periods of time $(5,15,30$, 45,60 , and $90 \mathrm{~min}$ ), washed, and fixed with $4 \%$ paraformaldehyde (PFA). When recycling was to be tested, cells that had been treated with agonist were washed in ice-cold PBS, and cells were incubated with fresh DMEM for an additional hour, after which cells were washed with PBS and fixed in $4 \%$ PFA for $5 \mathrm{~min}$ at $4^{\circ} \mathrm{C}$. Cells were directly analyzed microscopically or processed for immunofluorescence with rat anti-HA antibody (Roche) or Lyso-tracker dye (1: 20,000 dilution; BD PharMingen, San Diego, CA) using standard protocols.

Alkaline phosphatase-based surface expression assay. Sixty hours after transfection with the indicated constructs, COS7 cells were incubated with cycloheximide ( $40 \mu \mathrm{M})$ in DMEM for $1 \mathrm{~h}$. Cells were incubated with WIN 55,212-2 (100 nM) or vehicle as described above and then treated with primary anti-FLAG M1 antibody (Sigma, St. Louis, MO) in DMEM containing $5 \%$ horse serum at $4^{\circ} \mathrm{C}$ for $3 \mathrm{~h}$. Cells were washed, fixed with $4 \%$ PFA for $10 \mathrm{~min}$, and incubated for $30 \mathrm{~min}$ with the AP-linked antimouse antibody at room temperature, followed by washing with HBBS. Cells were then incubated with the $\mathrm{AP}$ assay reagent $\mathrm{A}$ at $37^{\circ} \mathrm{C}$ to visualize AP activity as described previously (Swiercz et al., 2004). The absorbance was measured at $605 \mathrm{~nm}$.

Biotin protection degradation assay. HEK 293 cells stably expressing $\mathrm{CB}_{1}$ were grown to confluency in poly-D-lysine-pretreated $10 \mathrm{~cm}$ plates. Before the experiment, a subset of plates were pretreated with the protease inhibitors $200 \mu \mathrm{M}$ chloroquine, $100 \mu \mathrm{M}$ leupeptin, and $50 \mu \mathrm{M}$ $\mathrm{NH}_{4} \mathrm{Cl}$ (Sigma) dissolved in water at $37^{\circ} \mathrm{C}$ for $60 \mathrm{~min}$. Next, all cells were treated with $3 \mu \mathrm{g} / \mathrm{ml}$ disulfide-cleavable biotin (Pierce, Rockford, IL) at $4^{\circ} \mathrm{C}$ for $30 \mathrm{~min}$, washed in TBS (in mM: $137 \mathrm{NaCl}, 25$ Tris-base, $3 \mathrm{KCl}$, and $1 \mathrm{CaCl}_{2}$ ) placed in DMEM with or without presence of protease inhibitors and treated with ligand ( $1 \mathrm{nM}$ to $1 \mu \mathrm{M}$ WIN 55,212-2) for the specified periods of time. Fresh ligand was added every $60 \mathrm{~min}$. All plates were washed in PBS, and remaining cell surface biotinylated receptors were stripped (50 mm glutathione, $0.3 \mathrm{M} \mathrm{NaCl}, 75 \mathrm{~mm} \mathrm{NaOH}$, and $1 \%$ fetal bovine serum) at $4^{\circ} \mathrm{C}$ for $30 \mathrm{~min}$. All plates were then quenched in buffer containing $9 \mathrm{mg} / \mathrm{ml}$ iodoacetamide and $10 \mathrm{mg} / \mathrm{ml}$ bovine serum albumin at $4^{\circ} \mathrm{C}$ for $20 \mathrm{~min}$, followed by cell lysis in buffer $(150 \mathrm{~mm} \mathrm{NaCl}, 25 \mathrm{~mm}$ $\mathrm{KCl}, 10 \mathrm{~mm}$ Tris- $\mathrm{HCl}$, and $0.1 \%$ Triton $\mathrm{X}-100$, $\mathrm{pH}$ 7.4) with added protease inhibitors (Complete; Roche) and $1 \mathrm{mg} / \mathrm{ml}$ iodoacetamide. Cellular debris was removed by centrifugation at $10,000 \times g$ at $4^{\circ} \mathrm{C}$ for $10 \mathrm{~min}$, and lysates were immunoprecipitated with anti-FLAG M2 antibodies linked with rabbit anti-mouse linker antibodies to Protein A Sepharose beads at $4^{\circ} \mathrm{C}$, washed extensively, and treated with PNGaseF at $37^{\circ} \mathrm{C}$ for $1 \mathrm{~h}$. Samples were denatured in SDS sample buffer with no reducing agent added, resolved by SDS/PAGE using 4-20\% Tris-glycine precast gels (Invitrogen, Carlsbad, CA), transferred to nitrocellulose membrane, overlaid with streptavidin (Vectastain $\mathrm{ABC}$ immunoperoxidase reagent; Vector Laboratories, Burlingame, CA), and finally developed with ECL plus reagents (GE Healthcare, Piscataway, NJ).

Generation of adeno-associated virus virions. The C-terminal 467 
amino acids of GASP1 (cGASP1) were amplified by PCR from mouse GASP1 cDNA (Whistler et al., 2002) and an HA tag was introduced C terminally in frame with cGASP1. This fragment was subcloned into a recombinant adeno-associated virus (rAAV) plasmid backbone containing the $1.1 \mathrm{~kb}$ cytomegalovirus enhancer/chicken $\beta$-actin (CBA) promoter, the woodchuck posttranscriptional regulatory element (WPRE), and the bovine growth hormone (bGH) poly(A) (Tappe et al., 2006). The same rAAV-CBA-WPRE-bGH backbone carrying the EGFP cDNA (Stratagene, La Jolla, CA) was used as control. AAV chimeric vectors were generated using helper plasmids encoding AAV1 and AAV2 at a ratio of $1: 1$ as described previously (Grimm et al., 2003). The cGASP1 fragment was also subcloned into a Semliki Forest virus (SFV) vector, and SFV virions were generated as described in detail by Wimmer et al. (2004). SFV virions were diluted 1:5000 in neuronal culture medium at days in vitro (DIV) 14, and infected neurons were used for coimmunoprecipitation experiments as described above at $18 \mathrm{~h}$ after SFV infection.

Analysis of $C B_{1}$ trafficking in primary neuronal cultures of spinal cord. Primary spinal neurons were cultured from embryonic rats at embryonic day 14 in Neurobasal medium with B27 supplement (1:50), L-glutamine (2 $\mathrm{mm})$, and penicillin/streptomycin (1:1000) and were allowed to mature for 2-3 weeks in vitro as described in detail previously (Tappe et al., 2006). In some experiments, cells were infected with AAV-HA-cGASP1 or AAV-EGFP $\left(\sim 10^{8}\right)$ at DIV 7 and assayed at DIV 20. Analysis of $\mathrm{CB}_{1}$ immunoreactivity localized on the cell surface was done using a surface labeling protocol. Cells were incubated with medium for $0-1 \mathrm{~h}$ (basal), WIN 52,212-2 (1.5 $\mu \mathrm{M})$ for $6,12,24$, and $48 \mathrm{~h}$, or vehicle for $6,12,24$, and $48 \mathrm{~h}$ in medium at $37^{\circ} \mathrm{C}$. Cells were washed with $\mathrm{PBS} / 5 \%$ serum two times for $5 \mathrm{~min}$ and incubated with anti- $\mathrm{CB}_{1}$ antibody (1:100 in culturing medium; Cayman Chemical) at $4^{\circ} \mathrm{C}$ for $1 \mathrm{~h}$. Cells were washed for three times for 5 min with $\mathrm{PBS} / 5 \%$ serum one time with $\mathrm{PBS}$ at $4^{\circ} \mathrm{C}$ and fixed for $10 \mathrm{~min} 4 \%$ PFA. Neurons were immunostained with anti-HA antibody (Roche) and anti-neurofilament 200 antibody (Chemicon) using anti-rat FITC, anti-rabbit tetramethylrhodamine isothiocyanate (TRITC), and anti-mouse cyanine 5 (Cy5) (all from Dianova, Hamburg, Germany) as described previously. EGFP, FITC, TRITC, or Cy5 fluorescence was imaged using a laser scanning confocal microscope (TCS AOBS; Leica, Bensheim, Germany). EGFP or FITC fluorescence was used to identify AAV-EGFP-infected or AAV-cGASP-HA-infected cells, respectively. Then TRITC and Cy5 fluorescence was scanned in a sequential scan mode to rule out bleed-through between channels. Scanning was first done on spinal neurons in the absence of agonist (basal) to determine the saturation limits for fluorescent signals. The gain of the photomultiplier tube then remained at a constant value, which was set below saturation limits. Neurons subjected to all of the different treatments were imaged under the same imaging parameters in a single scanning session. At least 10 neurons were scored from each group per experiment over a total of three independent culture experiments. Scanned images were analyzed using the Leica confocal software by recording fluorescence intensities over line profiles, which were superimposed directly on the stained neurites. At least 40 data points were collected per group per experiment.

In vivo injections of $A A V$ viruses. We previously described the injection of AAV virions in the spinal parenchyma of mice in detail (Tappe et al., 2006) (for more details, see Nature Protocols On-line). Briefly, adult mice were anesthetized with fentanyl/medetomidine/midazolam (4:6:16; $0.7 \mu \mathrm{l} / \mathrm{g}$, i.p.) and $300 \mathrm{nl}$ of a 2:1 mixture of AAV viral stocks with $20 \%$ Mannitol containing $1.2 \times 10^{7}$ virions were infused four times bilaterally (two times on each side) directly into the spinal parenchyma of spinal segments L3-L5 at a rate of $60 \mathrm{nl} / \mathrm{min}$ using a microprocessor-controlled minipump (World Precision Instruments, Sarasota, FL). These parameters yield a selective expression of proteins at the desired levels in spinal dorsal horn over $2-3 \mathrm{~mm}$ along the rostrocaudal axis without significant spread into the ventral horn. Mice were allowed to recover for 3 weeks before commencing behavioral analysis. At the end of the behavioral experiments, mice were killed, and the locus and time course of AAVinduced gene expression was monitored by EGFP fluorescence and immunohistochemistry using anti-HA antibodies on spinal sections.

Animal handling and nociceptive testing. All animal usage procedures were in accordance with ethical guidelines laid down by the local govern- ing body (Regierungspräsidium Karlsruhe, Karlsruhe, Germany). All behavioral measurements were done in awake, unrestrained, age-matched adult ( $>3$ months old) male C57BL/6 mice. The nociceptive tail-flick reflex was evoked by noxious heat applied via an infrared light source (Ugo Basile, Comerio, Italy) with a sensitivity of $0.1 \mathrm{~s}$ as described previously (Kolhekar et al., 1993). WIN 55,212-2 (2 mg/kg body weight) or vehicle (50\% DMSO) was injected intraperitoneally in mice, and tailflick latency was recorded after $1 \mathrm{~h}$.

Immunohistochemistry on mouse spinal cord and dorsal root ganglion, illustrations, and densitometry. Immunohistochemistry was performed as described in detail previously (Hartmann et al., 2004). Briefly, animals were perfused with $0.1 \mathrm{M}$ PBS and 4\% PFA. Spinal cords and dorsal root ganglia (DRGs) were isolated and postfixed for up to $16 \mathrm{~h}$ in $4 \%$ PFA. Free-floating sections of rat spinal cord (100 $\mu \mathrm{m}$, vibratome) and mouse spinal cord ( $50 \mu \mathrm{m}$, vibratome) were briefly microwaved in $10 \mathrm{~mm}$ citrate buffer (18 mm citric acid and $8.2 \mathrm{~mm}$ sodium citrate) for antigen retrieval. Immunohistochemistry was then performed using an anti-GASP1 antibody (Whistler et al., 2002), a rabbit anti- $\mathrm{CB}_{1}$ antibody (Cayman Chemicals), a goat anti- $\mathrm{CB}_{1}$ antibody (Ken Mackie, University of Washington, Seattle, WA), or mouse anti-HA tag (Babco, Berkley, CA) with the corresponding biotinylated secondary antibodies and standard reagent kits (Vectastain Elite ABC kit; Vector Laboratories, Burlingame, CA).

Bright-field images were taken using a cooled CCD camera (Leica) under similar illumination conditions. Staining intensity per unit area was measured densitometrically (Scion NIH Image software, version $\beta$ 4.0.2) over selected areas using unstained areas within the same section for background correction as described previously (Dreyer et al., 2003). Data was averaged from at least five areas per section and at least three sections per mouse. Frozen DRG sections (16 $\mu \mathrm{m}$, cryostat) were processed for immunofluorescence analysis using anti-GASP1 antibody (Whistler et al., 2002) and anti- $\mathrm{CB}_{1}$ antibody (Cayman Chemical), as described in detail previously (Dreyer et al., 2003). TRITC-conjugated isolectin-B4 $\left(\mathrm{IB}_{4}\right)$ was used to colabel nonpeptidergic nociceptive neurons (Dreyer et al., 2003).

Receptor autoradiography on mouse spinal cord. After behavioral experiments, mice were killed using $\mathrm{CO}_{2}$, and the spinal cords segments L4-L6 were rapidly extracted and frozen on dry ice. Cryosections $(16 \mu \mathrm{m})$ were incubated with $10 \mathrm{~nm}{ }^{3} \mathrm{H}-\mathrm{CP}-55940$ (2-[(1 R,2 R,5R)-5-hydroxy-2-(3hydroxypropyl)cyclohexyl]-5-(2-methyloctan-2-yl)phenol) (PerkinElmer, Wellesley, MA) for $2.5 \mathrm{~h}$ at $37^{\circ} \mathrm{C}$ and processed for autoradiography as described in detail previously (Rubino et al., 2005). Autoradiograms were generated by the incubation of tritium-sensitive film (Hyperfilm${ }^{3} \mathrm{H}$; GE Healthcare, Piscataway, NJ) with the sections for $7 \mathrm{~d}$. The signal intensity was determined by measuring gray levels using an image analysis system (Dual Scanner Artixscan 1800F and IMAGE-PRO-PLUS software) in the linear range after subtracting the background density.

Data analysis and statistics. All data are presented as mean \pm SEM. ANOVA for random measures was performed followed by post hoc Fisher's test to determine statistically significant differences. $p<0.05$ was considered significant.

\section{Results}

$\mathrm{CB}_{1}$ interacts physically with the C-terminal region of GASP1

GASP1 has been described to interact with several GPCRs harboring "FR" amino acids in their $\mathrm{C}$ terminus (Simonin et al., 2004). Because this sequence is present in the $C$ terminus of $C_{1}$ (9th and 10th amino acids after the seventh transmembrane: ... RSKDLRHAFR), we first addressed whether GASP1 could interact with $\mathrm{CB}_{1}$. HEK293 cells were cotransfected with N-terminally HA-tagged $\mathrm{CB}_{1}$ and N-terminally GFP-tagged GASP1. In transfected HEK293 cells as well as in brain lysates, we observed a prominent expression of full-length $\mathrm{CB}_{1}(\sim 60 \mathrm{kDa})$ and only a low level of expression of an $\sim 45 \mathrm{kDa}$ isoform (a putative N-terminal splice variant) (Shire et al., 1995) (supplemental Fig. 1 , available at www.jneurosci.org as supplemental material). $\mathrm{CB}_{1}$ could be coimmunoprecipitated with GASP1 using the anti-GFP antibody (Fig. 1A), and, conversely, an anti-HA antibody could 
immunoprecipitate GFP-GASP1 (Fig. $1 B)$. An HA-tagged fragment of GASP1 corresponding to the C-terminal 497 residues of GASP1 (called cGASP1 henceforth) (Whistler et al., 2002) was cotransfected with GFP-tagged $\mathrm{CB}_{1}$. $\mathrm{CB}_{1}$ could be coimmunoprecipitated with cGASP1 with the anti-HA antibody (Fig. 1C), and cGASP1 was coimmunoprecipitated with $\mathrm{CB}_{1}$ using an anti-GFP antibody (Fig. $1 D)$. These results show that heterologously coexpressed GASP1 and $\mathrm{CB}_{1}$ physically interact with each other and that the C terminus of GASP1 is sufficient to mediate this interaction.

Previous studies have shown that a mutant $\mathrm{CB}_{1}$ receptor lacking the last 14 residues does not internalize in HEK293 cells, whereas a mutant lacking the last 10 residues does (Hsieh et al., 1999). Particularly, the amino acids V460 and V464 have been implicated in mediating agonistinduced internalization of $\mathrm{CB}_{1}$ receptors (Hsieh et al., 1999). To address whether structural determinants of $\mathrm{CB}_{1}$ internalization are related to $\mathrm{CB}_{1}-\mathrm{GASP} 1$ interactions, we cotransfected constructs encoding HA-epitope-tagged $\mathrm{CB}_{1}$ mutants V460Z or V464Z (Fig. 1 E) with cGASP1 in HEK293 cells. Using anti-HA antibody, both $\mathrm{CB}_{1}$ mutants could be coimmunoprecipitated with cGASP1 (Fig. $1 E$ ), indicating that the motifs required for $\mathrm{CB}_{1}$ internalization do not play a role in the $\mathrm{CB}_{1}-\mathrm{GASP} 1$ interaction.

In cell lysates of the EGFP- $\mathrm{CB}_{1}$-expressing cell line, an anti-GFP antibody could coimmunoprecipitate endogenous fulllength GASP1 $(\sim 250 \mathrm{kDa})$ as well as its 110 kDa proteolytic product (Fig. $1 F$, left column), suggesting that overexpression of GASP1 is not required for interaction with $\mathrm{CB}_{1}$.

Interaction between $\mathrm{CB}_{1}$ and GASP1 in the nervous system in vivo

To determine whether $\mathrm{CB}_{1}$ can interact with GASP1 in vivo, we immunoprecipitated endogenous $\mathrm{CB}_{1}$ from rat brain lysates and performed Western blot analysis on the immunoprecipitates using an antiGASP1 polyclonal antibody, which has been characterized previously (Bartlett et al., 2005). Immunoreactive proteins of sizes expected for endogenous GASP1, 250 and $110 \mathrm{kDa}$, coprecipitated with $\mathrm{CB}_{1}$ (Fig. $1 F$ ), indicating that $\mathrm{CB}_{1}$ and GASP1 expressed endogenously in the nervous system interact with one other. Similar results were obtained from lysates of brains derived from wild-type mice but not from lysates derived from brains of $C B_{1}^{-1-}$ mice, demonstrating that both bands corresponding to GASP1 are coimmunoprecipitated in a $\mathrm{CB}_{1}$-dependent manner (supplemental Fig. 2, available at www.jneurosci.org as supplemental material).

A

C

E anti-GFP antibody (right).

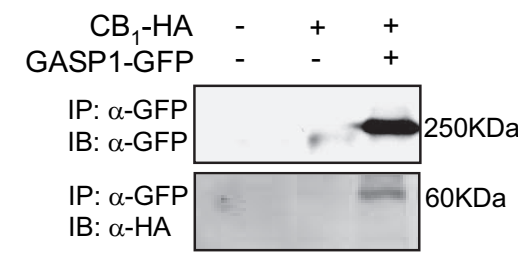

B
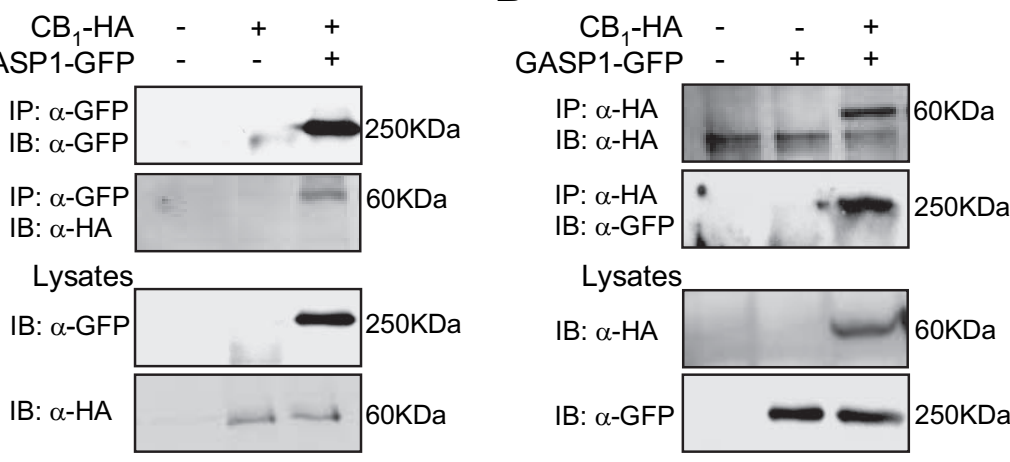

Lysates
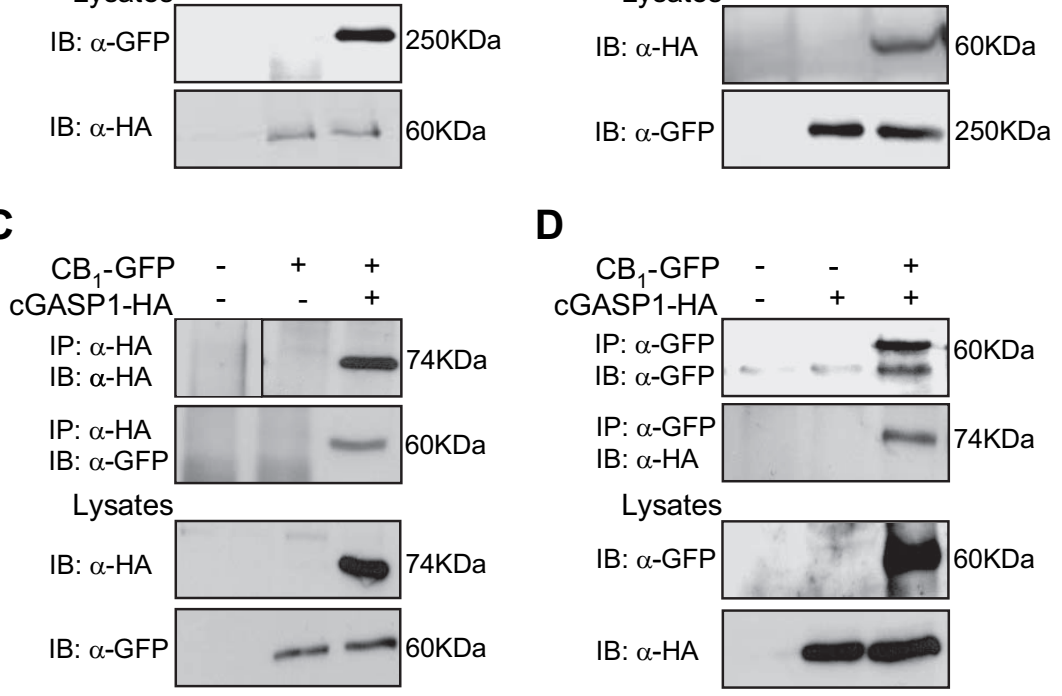

D

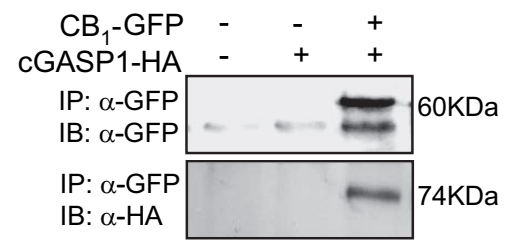

Lysates

IB: $\alpha$-GFP
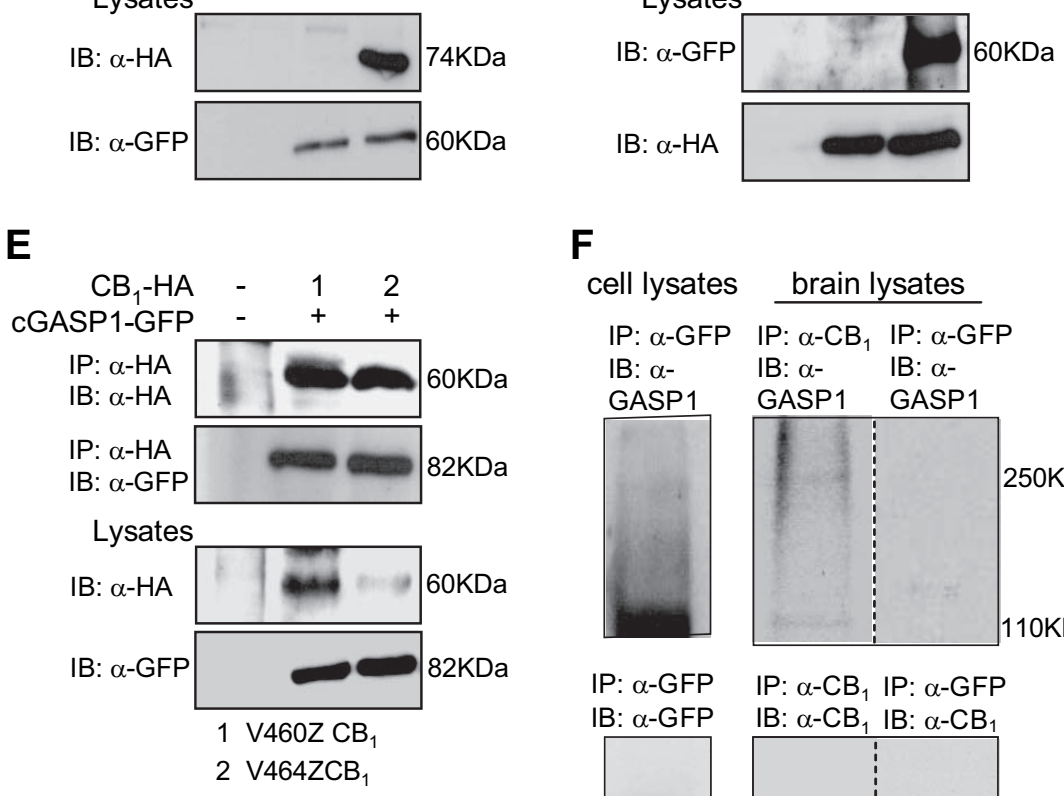

$\mathbf{F}$

cell lysates brain lysates

IP: $\alpha$-GFP IP: $\alpha-\mathrm{CB}_{1}$ IP: $\alpha-$ GFP

$\begin{array}{lll}\text { IB: } \alpha- & \text { IB: } \alpha- & \text { IB: } \alpha-\end{array}$

GASP1 GASP1 GASP1

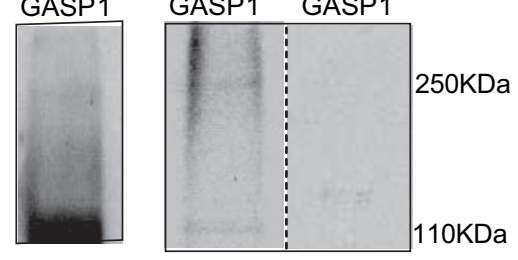

IP: $\alpha$-GFP $\quad$ IP: $\alpha-\mathrm{CB}_{1}$ IP: $\alpha$-GFP

IB: $\alpha$-GFP IB: $\alpha-\mathrm{CB}_{1}$ IB: $\alpha-\mathrm{CB}_{1}$

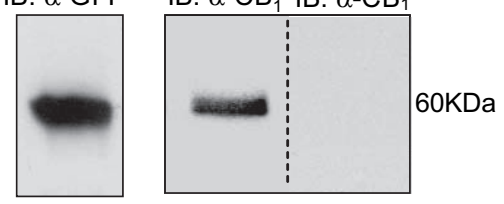

Figure 1. Coimmunoprecipitation from transfected $\mathrm{HEK} 293$ cells and rat brain demonstrate a physical interaction between $\mathrm{CB}_{1}$ and GASP1. In $\boldsymbol{A}-\boldsymbol{E}$, the two top panels represent Western blotting on immunoprecipitates (IP), and the bottom two panels represent Western blotting (IB) on cell lysates, which were used as starting material for coimmunoprecipitation. $A$, $H A$-tagged $C_{1}$ is coimmunoprecipitated with GFP-tagged GASP1 using an anti-GFP1 antibody. B, GFP-tagged GASP1 is coimmunoprecipitated with $\mathrm{HA}$-tagged $\mathrm{CB}_{1}$ using an anti-HA antibody. $C, D$, Coimmunoprecipitation of an HA-tagged mutant of GASP1 comprising the C-terminal 467 amino acids of GASP1 (CGASP1) and GFP-tagged CB 1 using an anti-HA antibody (C) or an anti-GFP antibody (D). $\boldsymbol{E}$, GFP-tagged cGASP1 coimmunoprecipitated with HA-tagged internalization-deficient mutants of $\mathrm{CB}_{1}, \mathrm{~V} 460 Z$ (1), and V464Z (2). $\boldsymbol{F}$, Endogenous GASP1 can be coimmunoprecipitated with CB $_{1}$ in an HEK293 cell line stably expressing GFP-CB ${ }_{1}$ using an anti-GFP antibody (left panels). Similarly, endogenous GASP1 can be coimmunoprecipitated with native $\mathrm{CB}_{1}$ from rat brain lysates using an anti-C $B_{1}$ antibody, as shown in the left. Specificity of this interaction is shown with a control coimmunoprecipitation using

\section{Agonist-induced trafficking of EGFP- $\mathrm{CB}_{1}$ monitored in HEK293 cells}

To visualize agonist-induced internalization of $\mathrm{CB}_{1}$ receptors and its modulation by potential interacting partner proteins, we generated HEK293 cell lines stably expressing $\mathrm{CB}_{1}$ receptors 
A
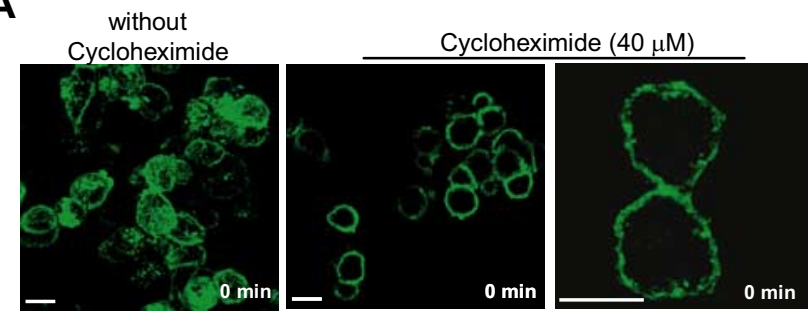

B
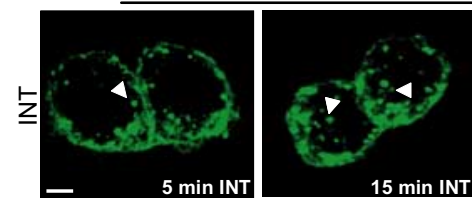

WIN $(100 \mathrm{nM})$
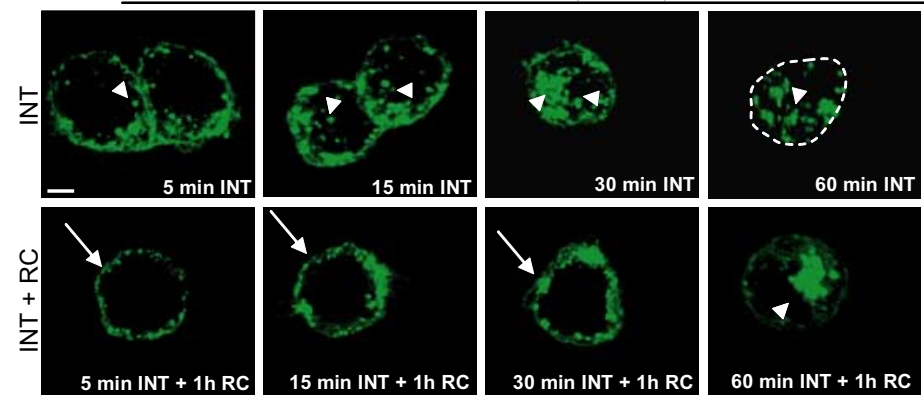

C
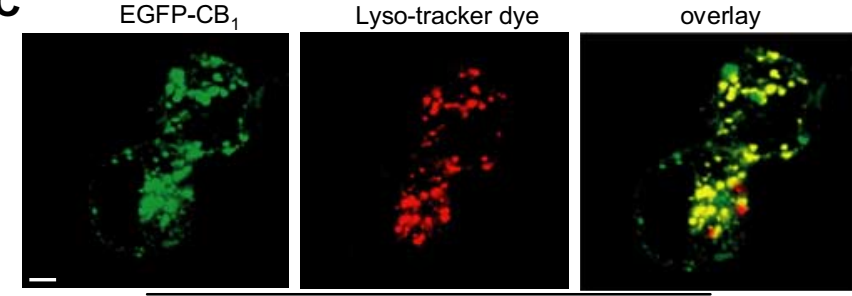

WIN (100 nM), 60 min internalization

Figure 2. Agonist-dependent internalization and lysosomal degradation of $C_{1}$ in a stable cell line expressing $N$-terminally EGFP-tagged $\mathrm{CB}_{1}$ demonstrated with confocal imaging. $A$, HEK293 cells stably expressing EGFP-CB 1 untreated cells (left) and cells treated for $1 \mathrm{~h}$ with $40 \mu \mathrm{m}$ cycloheximide (middle, right). 0 min indicates basal state before agonist exposure. Scale bars, $10 \mu \mathrm{m}$. $\boldsymbol{B}$, Treatment with a synthetic cannabinoid agonist, WIN 55,212-2 (WIN; $100 \mathrm{nm)} \mathrm{for} \mathrm{varying} \mathrm{periods} \mathrm{(5-90} \mathrm{min)} \mathrm{leads} \mathrm{to} \mathrm{inter-}$ nalization of EGFP-CB (INT; indicated by arrowheads). Additional incubation of cells for $1 \mathrm{~h}$ after termination of agonist exposure to allow recycling to the cell surface (RC) leads to recycling after agonist exposure over 5-10 min (arrows) but not after agonist exposure over 60-90 min (arrows). White dashed lines indicate the position of the cell membrane. $C$, Endocytic vesicles containing EGFP-CB 1 after an agonist exposure of 60 min colocalize with a lysosomal marker, Lyso-tracker dye (yellow puncta in overlay). Scale bars, $3 \mu \mathrm{m}$.

$\mathrm{N}$-terminally tagged with GFP. A cell line demonstrating moderate levels of GFP-CB ${ }_{1}$ expression uniformly in $>90 \%$ of cells was selected for additional analysis (Fig. 2A). To prevent confounding the analysis of agonist-induced $\mathrm{CB}_{1}$ trafficking by $\mathrm{CB}_{1}$ synthesized de novo during the experiment, all experiments were performed in the acute presence of a protein synthesis inhibitor, cycloheximide, which clearly revealed the pool of GFP-CB $\mathrm{CB}_{1}$ in the vicinity of the cell surface (Fig. $2 \mathrm{~A}$, middle, right). Our results differ from that of Leterrier et al. (2004) over this point, a discrepancy that could be explained on the basis of differences caused by levels and mode of expression (transient vs stable transfection) and the location of the EGFP tag [N-terminal here vs $\mathrm{C}$-terminal tag used by Leterrier et al. (2004)]. We then characterized the time course and nature of GFP-CB ${ }_{1}$ internalization and trafficking during exposure to a $\mathrm{CB}_{1} / \mathrm{CB}_{2}$ agonist, WIN 55,122-2 (100 $\mathrm{nM})$. Confocal analysis revealed that exposure to WIN over short periods of time (5-30 $\mathrm{min}$ ) led to rapid internalization that was obvious within $5 \mathrm{~min}$ and marked starting with a 30 min exposure (Fig. $2 B$, top row, arrowheads). Termination of agonist exposure at 5 or $30 \mathrm{~min}$ led to a near complete recycling of the internalized receptors to the cell membrane within $60 \mathrm{~min}$ (Fig. $2 B$, bottom row, arrows). In contrast, after exposure to WIN over
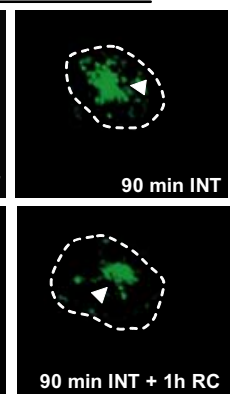

longer periods (60-90 $\mathrm{min}$ ), the internalized receptors did not recycle appreciably back to the cell surface when tested at 60 min after termination of agonist exposure (Fig. 2B, bottom row, arrowheads). Indeed, endocytotic vesicles containing EGFP- $\mathrm{CB}_{1}$ after a $60 \mathrm{~min}$ exposure to WIN primarily colocalized with a lysosomal marker, Lyso-tracker (Fig. 2C), showing that $\mathrm{CB}_{1}$ was sorted into lysosomes after prolonged agonist exposure. Similar results were obtained after visualizing the trafficking of Flag-tagged $\mathrm{CB}_{1}$ in HEK293 cells (supplemental Fig. 3, available at www.jneurosci.org as supplemental material). Furthermore, our results are similar to a previous report on expression of untagged $\mathrm{CB}_{1}$ in AtT20 cells (Hsieh et al., 1999), thereby indicating that the EGFP$\mathrm{CB}_{1}$-expressing stable cell line used here reliably reproduces aspects of wild-type $\mathrm{CB}_{1}$ receptor trafficking and can be used for addressing underlying molecular mechanisms.

\section{cGASP1 modulates trafficking of EGFP- $\mathrm{CB}_{1}$ during agonist exposure in HEK293 cells}

Previous studies have established that a fragment corresponding to the $\mathrm{C}$-terminal 497 residues of GASP1 (cGASP1) competes with the binding of full-length GASP1 to GPCRs and can be therefore used as a dominant-negative tool to probe the functional relevance of GASP1-GPCR interactions (Whistler et al., 2002; Simonin et al., 2004; Bartlett et al., 2005). We therefore transfected the EGFP- $\mathrm{CB}_{1}$ stable cell line with HA-tagged cGASP1 or a control vector and compared WIN-induced internalization and recycling. The basal levels and pattern of distribution of EGFP- $\mathrm{CB}_{1}$ was comparable in vector-transfected cells and cGASP1-transfected cells (Fig. 3A, left column, $0 \mathrm{~min}$ ). After a 30 or $90 \mathrm{~min}$ exposure to WIN, both vector-transfected cells and cGASP1-transfected cells showed internalization of EGFP- $\mathrm{CB}_{1}$, which was similar to that observed in untransfected cells (Fig. $3 A$, arrowheads). We then studied recycling of EGFP-CB ${ }_{1}$ to the cell surface at $60 \mathrm{~min}$ after termination of varying periods of exposure to WIN. Like untransfected cells (Fig. 2 above), vector-transfected cells and cGASP1-trasfected cells showed recovery of a substantial proportion of internalized receptors at the cell surface when cells had been exposed to WIN for $30 \mathrm{~min}$ (Fig. $2 \mathrm{~B}$, left panels, arrows). Consistent with our results from untransfected cells (Fig. 2 above), vector-transfected cells exposed to WIN for 90 min showed very little recovery of EGFP- $\mathrm{CB}_{1}$ at $60 \mathrm{~min}$ after termination agonist treatment (Fig. $3 B$, top middle, arrowhead). In striking contrast, cGASP1expressing cells demonstrated substantial recovery of EGFP-CB to the cell surface under the same conditions (Fig. 3B, bottom middle, arrows). Because cGASP1 expression did not seem to alter agonist-induced internalization (Fig. $3 \mathrm{~A}$ above), the increased recovery of EGFP-CB ${ }_{1}$ at the cell surface likely reflects increased recycling of internalized receptors back to the cell sur- 
A
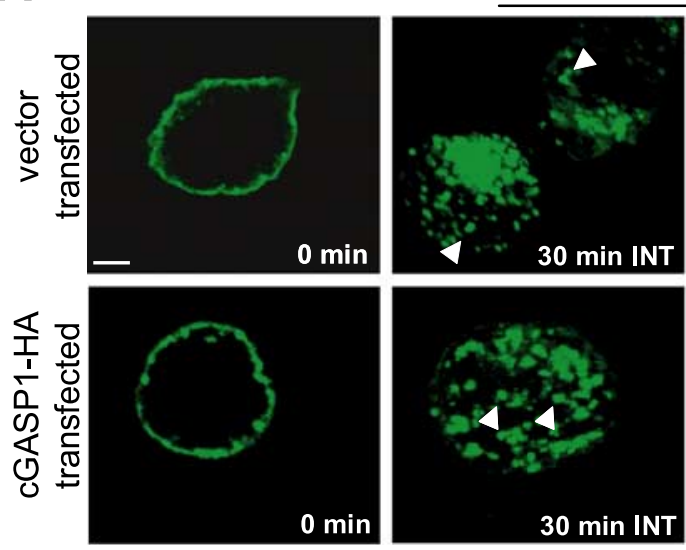

B
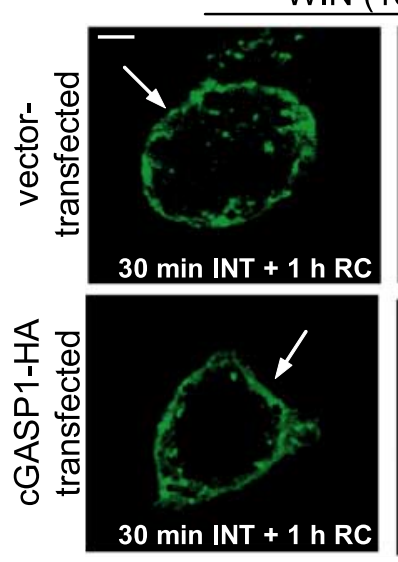

C

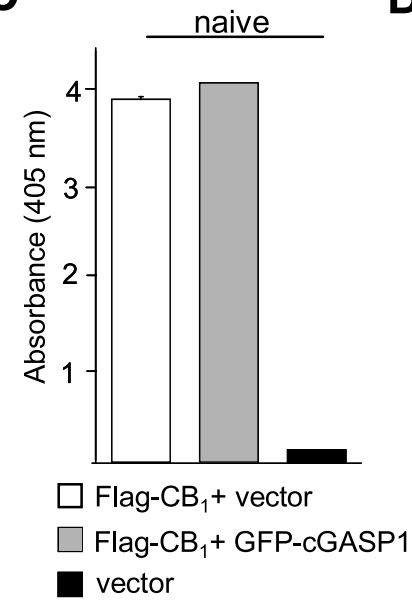

E
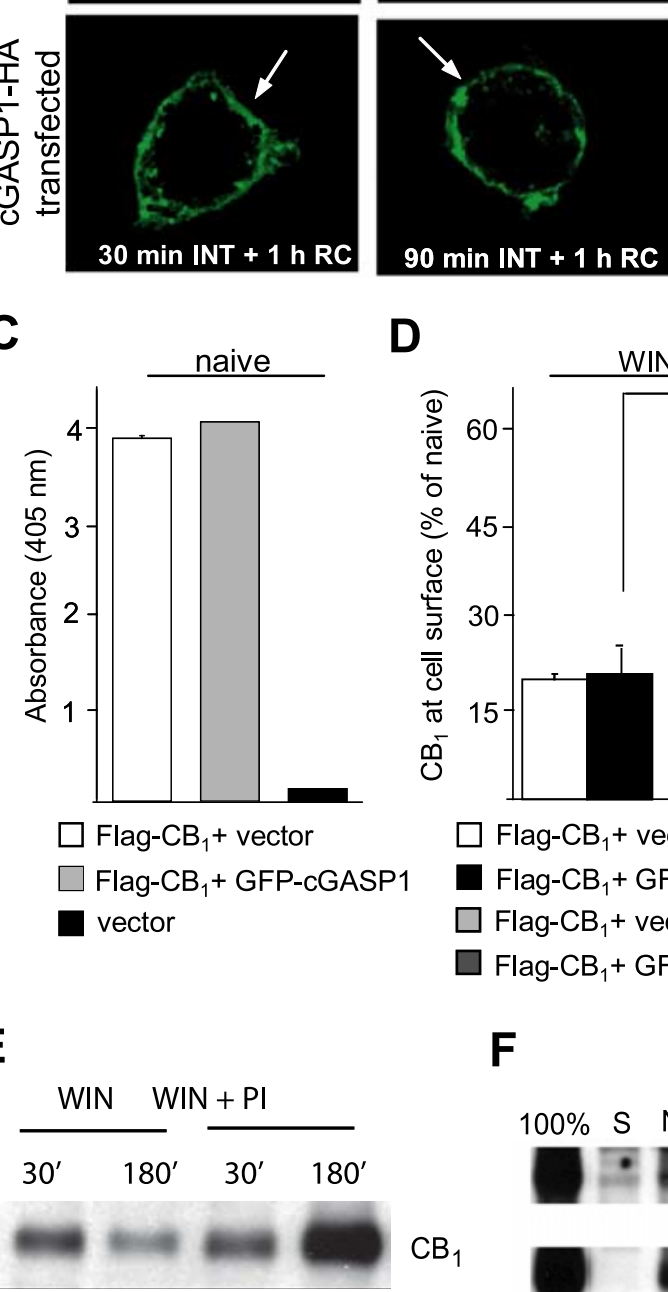

D

$\mathbf{F}$
WIN (100 nM)
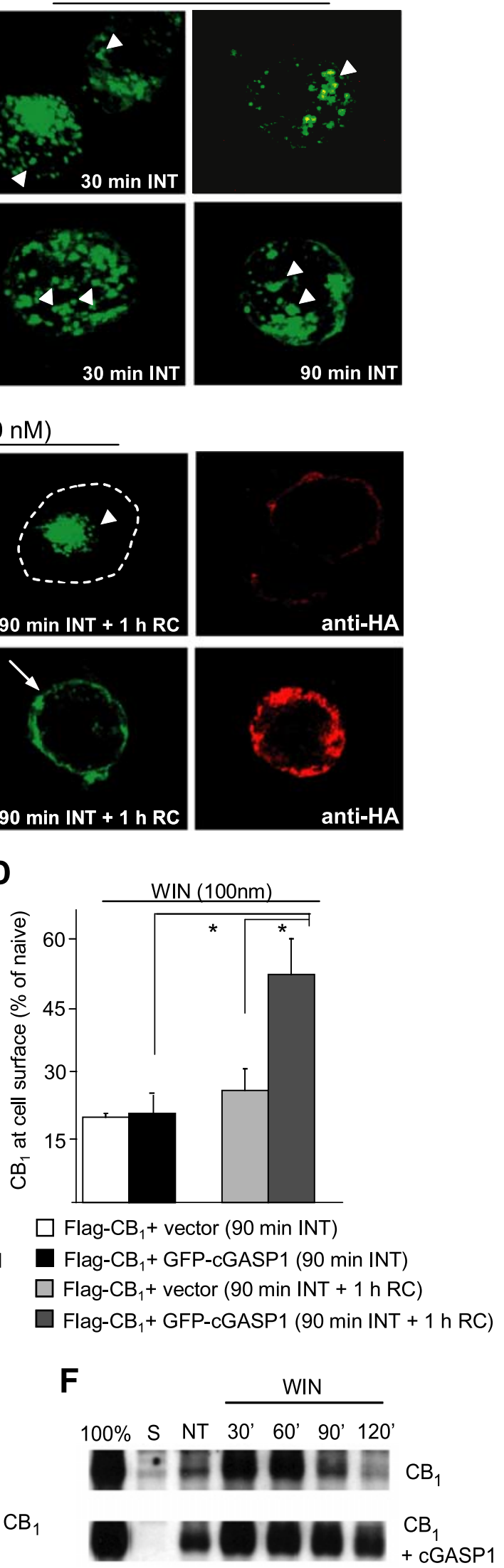

Figure 3. A dominant-negative mutant of GASP1 attenuates recycling of EGFP-CB 1 without affecting surface expression or WIN-induced internalization. All experiments were done after acute $(1 \mathrm{~h})$ pretreatment with cycloheximide (40 $\mu \mathrm{M})$. The EGFP$\mathrm{CB}_{1}$ stable cell line was transfected with an HA-tagged dominant-negative mutant of GASP1 (cGASP1-HA) or empty vector in $A$ and $\boldsymbol{B}$. $\boldsymbol{A}$, Vector-transfected and CGASP1-HA-transfected cells show internalization of EGFP-CB ${ }_{1}$ (arrowheads; INT) after treat-

face. These results suggest that, in the presence of cGASP1, degradation of $\mathrm{CB}_{1}$ induced by long-term agonist exposure is reduced and recycling to cell surface is enhanced.

\section{Quantitative estimation of cell surface} $\mathrm{CB}_{1}$ expression in the presence

\section{of cGASP1}

To consolidate these observations via an independent and quantitative method of estimation, we used an AP-based assay (Swiercz et al., 2004) for quantifying cell surface expression of heterologously expressed $\mathrm{CB}_{1}$. Before agonist exposure (basal), the level of $\mathrm{CB}_{1}$ expression at the cell membrane in the acute presence of cycloheximide was similar in cells transfected with $\mathrm{CB}_{1}$ plus vector and cells transfected with $\mathrm{CB}_{1}$ plus GFP-tagged cGASP1 (Fig. 3C). During a $90 \mathrm{~min}$ exposure to WIN, cell surface expression of $\mathrm{CB}_{1}$ dropped significantly in cells transfected with $\mathrm{CB}_{1}$ plus vector $(19 \pm 1 \%$ of basal levels) (Fig. 3D, white bar), as well as in

$\leftarrow$

ment with WIN (100 nm) for 30 or 90 min. B, After termination of a 30 min WIN exposure, incubation of treated cells for $1 \mathrm{~h}$ $(\mathrm{RC})$ led to recycling of EGFP-CB $\mathrm{B}_{1}$ to the cell membrane (arrows) in vector-transfected cells and cGASP1-HA-transfected cells. In contrast, during incubation of treated cells for $1 \mathrm{~h}$ (RC) after termination of a 90 min WIN exposure, CGASP1-HAtransfected cells show recycling of EGFP-CB to the cell membrane (arrows), whereas vector-transfected cells do not (arrowheads; white dashed line indicates position of the cell membrane). Panels at the right show expression of HAtagged CGASP1 via anti-HA immunoreactivity. Scale bars: $A$, $B, 3 \mu \mathrm{m}$. $\boldsymbol{C}, \boldsymbol{D}, \mathrm{A}$ quantitative cell surface expression assay based on activity of AP was performed on COS7 cells transfected with $\mathrm{N}$-terminally FLAG-tagged $\mathrm{CB}_{1}$ plus empty vector, FLAG-tagged $C_{1}$ plus GFP-tagged CGASP, or empty vector alone (for details, see Materials and Methods). AP activity (a measure of $C B_{1}$ expression at the cell membrane) was not affected by expression of $\mathrm{GASP}$ in the naive state (C). During a 90 min exposure to WIN (100 nM), AP activity decreased in both treatment groups, indicating internalization (INT; white and black bars). $\boldsymbol{D}$, Additional incubation of cells for $1 \mathrm{~h}$ after termination of a 90 min WIN exposure to allow recycling to the cell surface $(\mathrm{RC})$ leads to recycling in cells expressing $C_{1}$ plus CGASP1 (dark gray bar) but not in cells expressing $C_{1}$ plus vector (light gray bar). ${ }^{*} p<0.05$, ANOVA followed by Fisher's test. $n=3$ independent culture experiments each in duplicates in all panels. $\boldsymbol{E}$, The stability of internalized $\mathrm{CB}_{1}$ was assessed using a biotin protection assay. HEK293 cells stably expressing $\mathrm{CB}_{1}$ were biotinylated and treated with $1 \mu \mathrm{m}$ WIN $55,212-2$ for the times indicated before stripping with membrane-impermeant reducing agent. The "protected" internalized receptor pool was then immunoprecipitated and visualized. $C B_{1}$ degrades after internalization by WIN $55,212-2$, which can be reduced by adding the proteolysis inhibitors (PI). $\boldsymbol{F}$, The stability of the internalized $\mathrm{CB}_{1}$ was assessed in cells stably expressing $C_{1}$ alone or expressing $C_{1}$ and overexpressing CGASP using a biotin protection assay. Overexpression of cGASP $\sim 100$-fold over endogenous GASP delayed degradation of the $\mathrm{CB}_{1}$. S, Stripped; $\mathrm{NT}$, nontreated. 
A
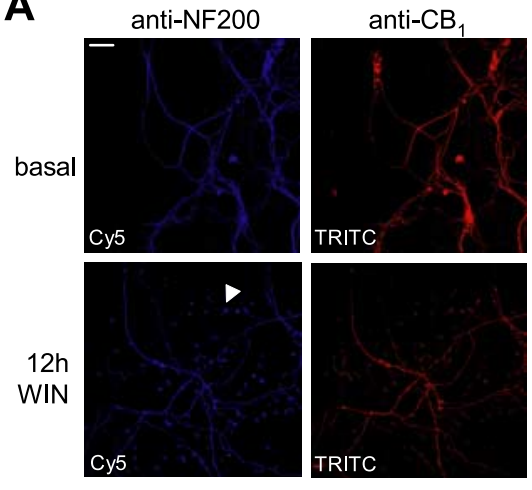

$12 \mathrm{~h}$
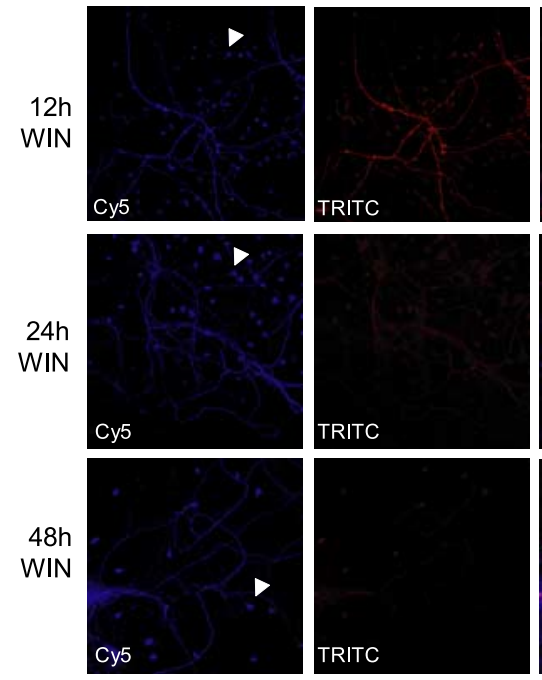

B

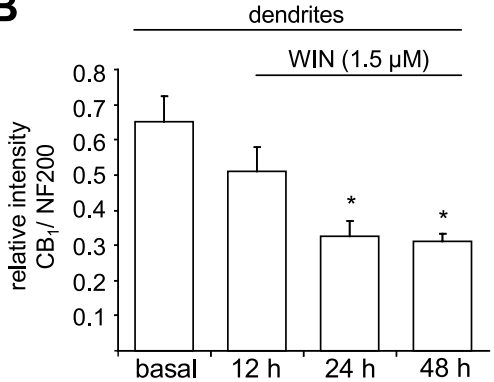

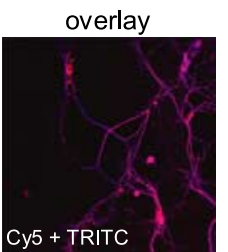
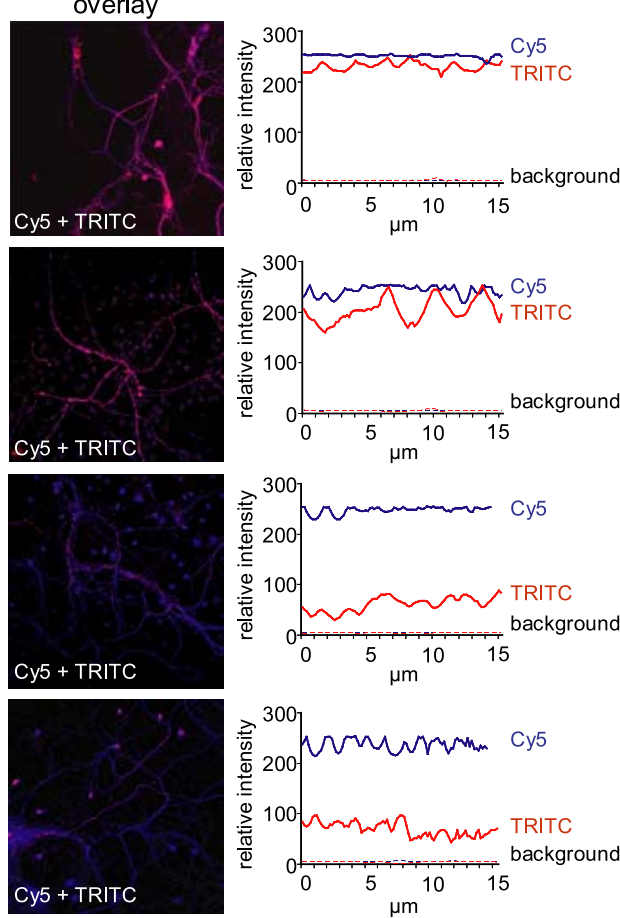

soma

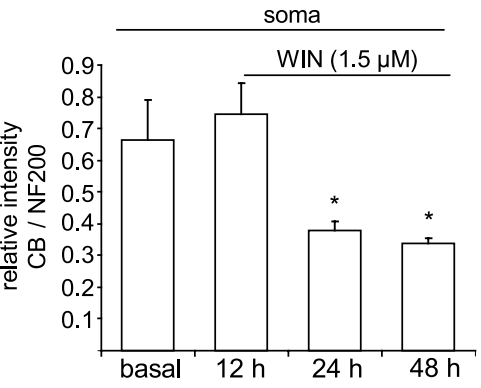

Figure 4. Analysis of $C B_{1}$ downregulation from the surface of primary cultured rat spinal cord neurons during prolonged treatment with WIN $(1.5 \mu \mathrm{m})$. A surface-labeling protocol was used to assess surface expression of $\mathrm{CB}_{1}(\mathrm{TRITC})$ and stained cultures were fixed and immunostained with an anti-neurofilament 200 (NF200) antibody (Cy5), as an internal control. All images were taken in the same imaging conditions, and all signals were below saturation limits. $\boldsymbol{A}$, Typical examples of confocal images acquired in the sequential mode representing a high level of $C B_{1}$ expression at the surface of spinal neurites in the naive state (basal) and WIN-induced decrease in surface $C_{1}$ expression $(12,24$, and $48 \mathrm{~h}$ ). Line profiles on the right demonstrate the intensity of the signals (solid lines) and background (dashed lines). $\boldsymbol{B}$, Quantitative estimation of $\mathrm{CB}_{1}$ expression at the surface of spinal neurites or soma as a fraction of the corresponding neurofilament 200 expression. Significant downregulation is observed after WIN treatment for 24 or $48 \mathrm{~h}\left({ }^{*} p<0.05\right.$, ANOVA, post hoc Fisher's test). $n=40$ data points each per group. Scale bar, $40 \mu \mathrm{m}$. pool of $\mathrm{CB}_{1}$ after prolonged treatment with WIN (Fig. 3D), which was reduced during treatment with proteolysis inhibitors (Fig. 3D). Similarly, when GFPcGASP was coexpressed with $\mathrm{CB}_{1}$ at levels 100-fold over endogenous GASP (data not shown), the stability of internalized $\mathrm{CB}_{1}$ was remarkably enhanced (Fig. 3E). Thus, the overexpression of dominant-negative cGASP delayed degradation of the $\mathrm{CB}_{1}$, suggesting that postendocytic sorting of the $\mathrm{CB}_{1}$ to the lysosomal degradation pathway is mediated by GASP.

\section{Trafficking of native $\mathrm{CB}_{1}$ in spinal neurons}

To place these findings in a more physiological context, we then studied $\mathrm{CB}_{1}$ trafficking in primary spinal neurons, which were cultured from rat embryonic spinal cord and allowed to mature for 3 weeks in vitro. In cultures derived thus, a majority of large neurons with large, arborized neurites demonstrated intense immunoreactivity for $\mathrm{CB}_{1}$ (data not shown). A large number of small neurons with very short processes (Fig. 4A, arrowheads) demonstrated only very weak $\mathrm{CB}_{1}$ immunoreactivity restricted to the cell soma and were not taken into account for this analysis.

Cell surface $\mathrm{CB}_{1}$ was selectively analyzed using a standard surface staining protocol, and neurofilament 200, a protein widely and stably expressed in neurons, served as an internal control for the integrity and state of the neuron (typical examples are shown in Fig. 4A). Laser scanning confocal microscopy in the sequential mode enabled quantitative assessment of agonist-induced changes in surface staining for $\mathrm{CB}_{1}$ as a function of total neurofilament 200 expression in a large population of neurites in the naive state (basal) and at different time points after exposure to WIN (Fig. 4B).

In the naive state, surface labeling of cGASP-expressing cells (20 $\pm 5 \%$ of control levels) (Fig. $3 D$, black bar), indicating that agonist-induced internalization was not affected by cGASP expression $(F=0.0099 ; p=0.924)$. When cells were tested for recycling at $60 \mathrm{~min}$ after a $90 \mathrm{~min}$ exposure to WIN, cells transfected with $\mathrm{CB}_{1}$ plus vector failed to demonstrate significant recycling to the cell surface $(25 \pm 5 \%$ of basal; $F=$ 1.731; $p=0.236$ compared with internalization alone) (Fig. $3 D$, light gray bar). In striking contrast, cells expressing cGASP demonstrated significant recovery of $\mathrm{CB}_{1}$ expression at the cell surface ( $51 \pm 8 \%$ of control; $F=7.834 ; p=0.031$ compared with internalization alone) (Fig. $3 D$, dark gray bar). This was significantly higher than recovery in vector-transfected cells $(F=11.329 ; p=$ $0.015)$. Thus, these results verify that cGASP1 promotes recycling of internalized $\mathrm{CB}_{1}$ to the cell surface.

We then used a biotin protection assay to assess the effects of cGASP1 on the stability of internalized $\mathrm{CB}_{1}$ in cells stably expressing $\mathrm{CB}_{1}$. Considerable degradation was found in the internalized
$\mathrm{CB}_{1}$ yielded strong staining in neurites (TRITC channel in Fig. $4 A$, top). During a $6 \mathrm{~h}$ exposure to WIN, there was no change in the surface labeling of $\mathrm{CB}_{1}$ (data not shown), and a $12 \mathrm{~h}$ exposure only led to a trend of a decrease in surface $\mathrm{CB}_{1}$ expression in neuronal neurites (Fig. $4 A, B$ ). In contrast, when neurons were treated for $24 \mathrm{~h}$ with WIN, surface expression of $\mathrm{CB}_{1}$ in neurites dropped by nearly $50 \%$ (typical examples in Fig. $4 A$, compare purple overlay at $24 \mathrm{~h}$ with pink overlay in the basal state; $B$, left) $(F=14.532 ; p=0.004)$. A similar course of WIN-induced internalization was observed after analyzing cell surface expression of $\mathrm{CB}_{1}$ over the soma of the treated neurons (Fig. $4 B$, right) $(F=$ 7.932; $p=0.023$ ). Protracted exposure to WIN for $48 \mathrm{~h}$ did not increase in the level of WIN-induced downregulation of $\mathrm{CB}_{1}$ in neurites or soma (Fig. $4 A, B)(F=22.418, p<0.001$ at $48 \mathrm{~h}$ in neurites; $F=13.268, p=0.005$ at $48 \mathrm{~h}$ in soma). These results show that prolonged treatment with a cannabinoid leads to a marked loss of endogenous $\mathrm{CB}_{1}$ from the surface of neurites of 
A

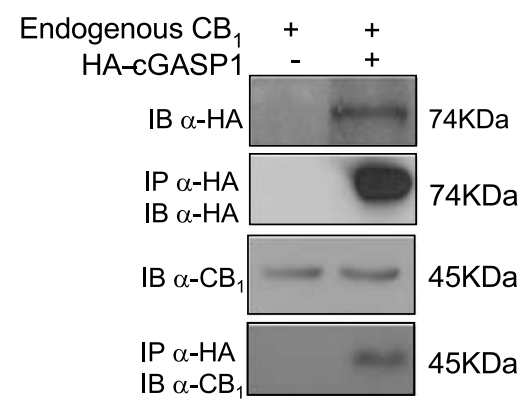

D

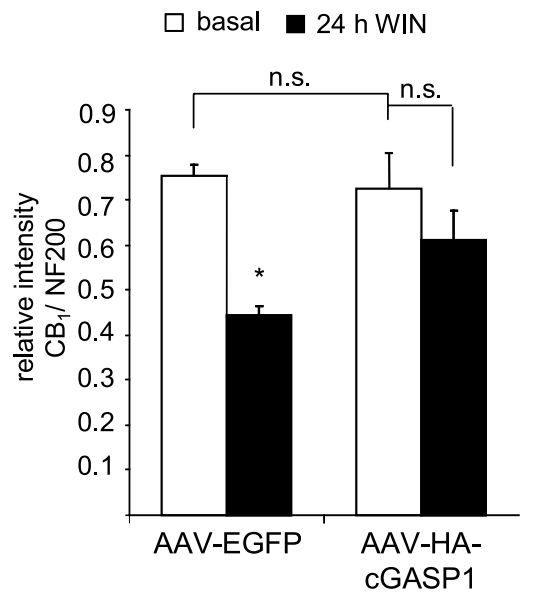

B

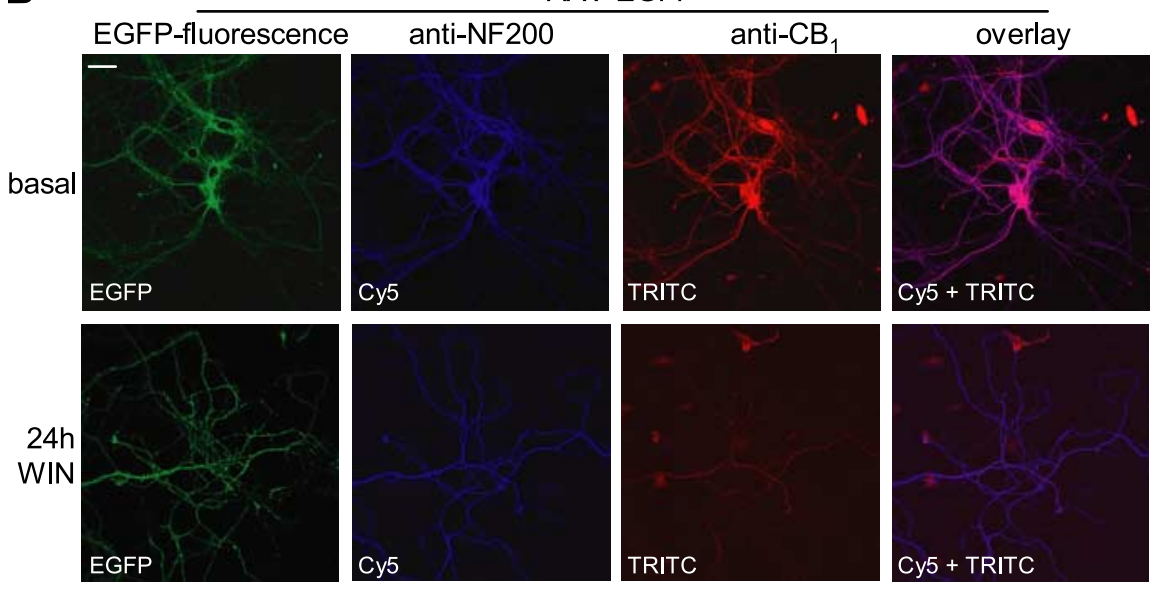

C
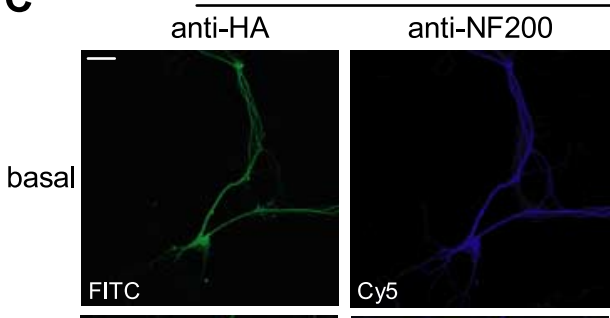

AAV-HA-cGASP1

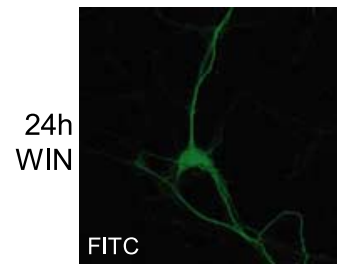

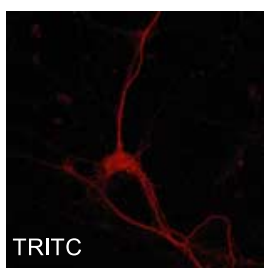
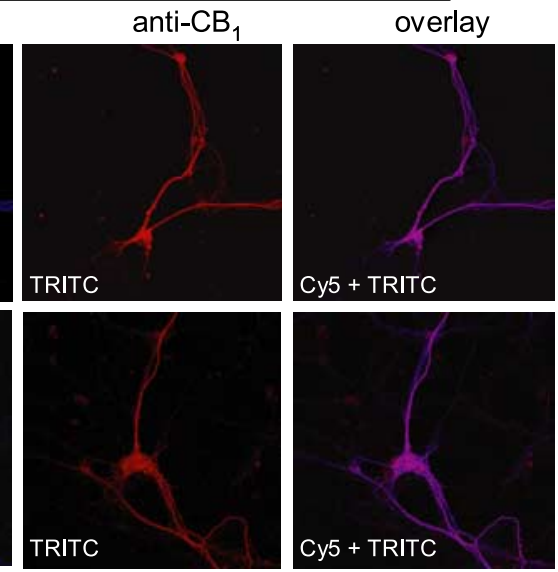

Figure 5. A dominant-negative mutant of GASP1 (CGASP1) attenuates WIN-induced downregulation of $\mathrm{CB}_{1}$ from the surface of primary cultured rat spinal neurons. A surface-labeling protocol was used to assess surface expression of CB1 (TRITC), and stained cultures were fixed and immunostained with an anti-neurofilament 200 (NF200) antibody (Cy5) to normalize CB, immunoreactivity. $A$, HA-tagged CGASP1 was virally transduced in cultured spinal neurons. An anti-HA antibody could coimmunoprecipitate CGASP1 and endogenous $\mathrm{CB}_{1}$ from lysates of spinal neurons. IP, Immunoprecipitation; IB, immunoblot. $B$, EGFP was overexpressed in cultured spinal neurons via an AAV vector. Typical examples of confocal images representing a high level of $C_{1}$ expression at the surface of spinal neurites in the naive state (basal) and decrease in surface $\mathrm{CB}_{1}$ expression after a $24 \mathrm{~h}$ exposure to WIN $(1.5 \mu \mathrm{M})$ are shown. $C$, HA-tagged $\mathrm{GGASP} 1$ was overexpressed in spinal neurons via an $A A V$ vector and was recognized via anti-HA immunofluorescence using FITC-labeled antibodies. Typical examples of confocal images representing levels of $C_{1}$ expression at the surface of spinal neurites in the naive state (basal) or after a $24 \mathrm{~h}$ exposure to WIN $(1.5 \mu \mathrm{m})$ are shown. Note that CGASP1-expressing neurons do not show a marked downregulation of $\mathrm{CB}_{1}$ during WIN treatment, as EGFP-expressing neurons do $(\boldsymbol{B})$. $\boldsymbol{D}$, Quantitative estimation of $\mathrm{CB}_{1}$ expression at the surface of spinal neurites as a fraction of the corresponding neurofilament 200 expression. Significant downregulation is observed after a $24 \mathrm{~h}$ WIN treatment over basal in EGFP-expressing neurites but not in cGASP1-expressing neurites. $n=40$ data points per group. ${ }^{*} p<0.05$, ANOVA, post hoc Fisher's test. n.s., Nonsignificant. Scale bars: $B, C, 40 \mu \mathrm{m}$.

primary spinal neurons, albeit with delayed kinetics compared with $\mathrm{CB}_{1}$ expressed heterologously in HEK293 cells.

\section{Effects of cGASP1 on trafficking of native $\mathrm{CB}_{1}$ in spinal neurons}

In Figure $1 E$, we showed that cGASP1 efficiently associates with heterologously expressed $\mathrm{CB}_{1}$ in HEK293 cells. To ascertain that cGASP1 can also interact with endogenous $\mathrm{CB}_{1}$ in neurons, we transduced cultured spinal neurons with SFV virions expressing HA-tagged cGASP1. Indeed, an anti-HA antibody coimmunoprecipitated endogenous $\mathrm{CB}_{1}$ with HA-cGASP1 in neurons transduced with SFV-HA-cGASP1 but not in naive neurons (Fig. 5A). Interestingly, in contrast to the brain, the $45 \mathrm{kDa}$ form of $\mathrm{CB}_{1}$ corresponding to a putative $\mathrm{N}$-terminal splice variant of $\mathrm{CB}_{1}$ (Shire et al., 1995) was found to be predominantly expressed in cultured spinal neurons, and the $60 \mathrm{kDa}$ form was found at low levels only (supplemental Fig. 1, available at www.jneurosci.org as supplemental material). We then addressed whether GASP1 contributes to downregulation of $\mathrm{CB}_{1}$ at the surface of neurites after prolonged agonist exposure in spinal neurons. To enable long-lasting expression of cGASP 1 in cultured spinal neurons, we generated recombinant chimeric adeno-associated Virus-1/2 virions (rAAV1/2) (During et al., 2003) expressing HA-tagged cGASP1 (AAV-cGASP1). AAV1/2 virions expressing EGFP served as controls (see below). Transduction of AAVcGASP1-HA virions led to a rapid and readily detectable expression of HA-tagged cGASP1 in a large number of exposed neurons within $12 \mathrm{~h}$ (see below).

Primary spinal neurons expressing AAV-EGFP1 or AAVcGASP1-HA were visualized via EGFP fluorescence or anti-HA immunoreactivity (Fig. $5 B, C$, left, green fluorescence). The fate of internalized native $\mathrm{CB}_{1}$ receptors in these neurons after WIN exposure was monitored in triple-labeling experiments via confocal microscopy (Fig. 5B). Scanning was done in sequential mode to absolutely rule out bleed-through of signals across channels. Similar to naive, untransduced neurons (Fig. 4, above), neurons transduced with AAV-EGFP showed a significant loss of cell surface $\mathrm{CB}_{1}$ in neurites after a $24 \mathrm{~h}$ exposure to WIN (compare 
A

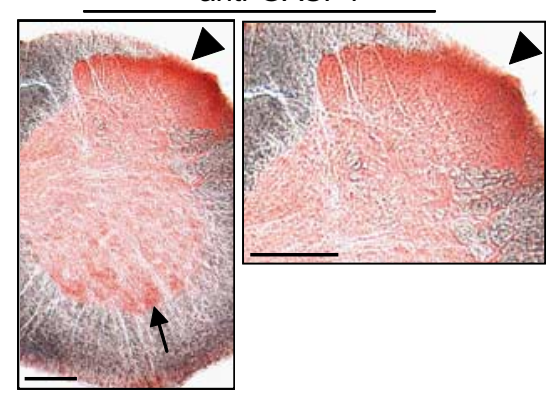

B

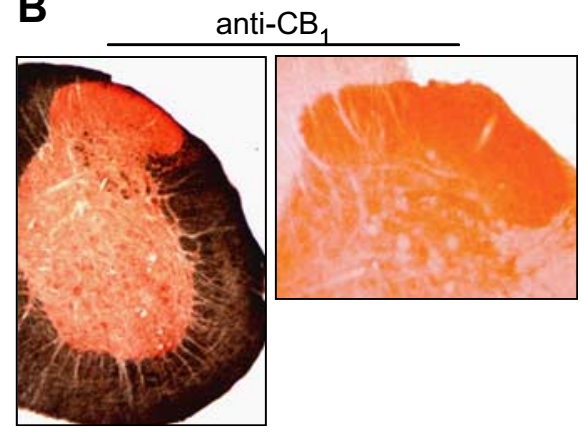

C
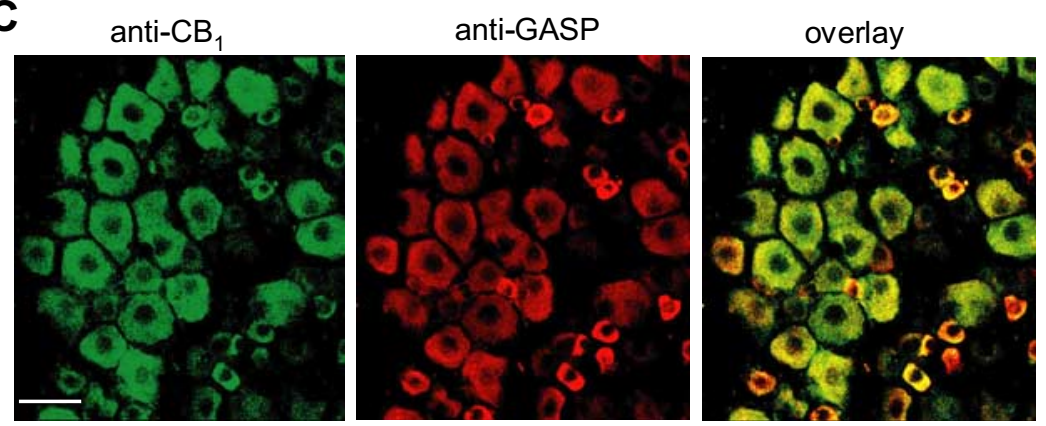

D

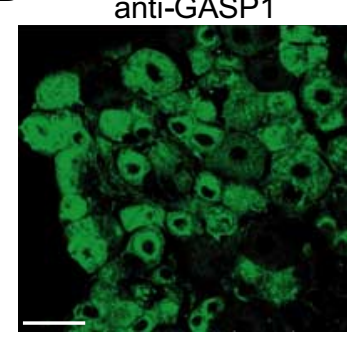

anti-CB
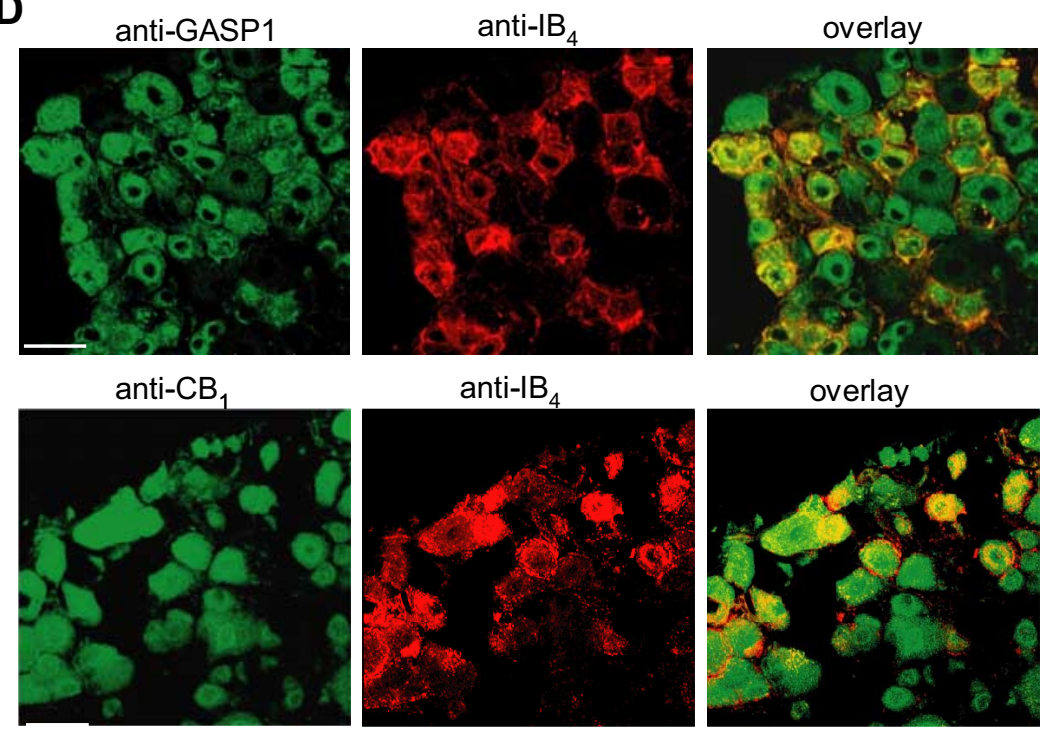

anti-IB 4
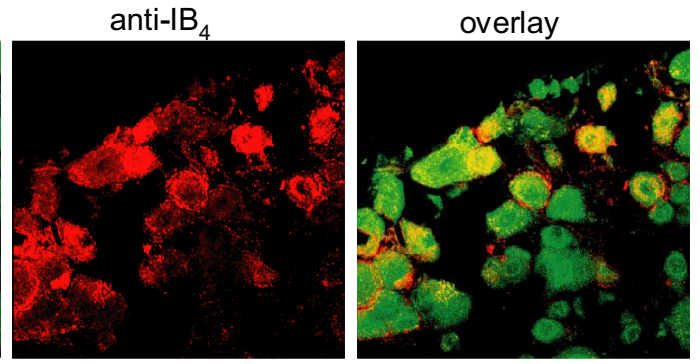

Figure 6. Pattern of GASP1 immunoreactivity over mouse spinal sensorimotor circuits processing nociceptive inputs. $A$, GASP1 immunoreactivity is found throughout the spinal cord and is particularly abundant in superficial laminas of the spinal dorsal horn (arrowheads; magnified in panel at the right) and in spinal motor neurons (arrow). $B$, Immunoreactivity for $C_{1}$ is also found throughout the spinal dorsal horn and is also dense in the most superficial lamina. $C$, Dual-immunofluorescence experiments using a rabbit anti-GASP1 antibody and a goat anti-C $B_{1}$ antibody on sections of DRG reveal a high degree of colocalization between endogenous $G A S P 1$ and native $C_{1}$. D , Immunofluorescence labeling of DRG sections shows that GASP1 as well as $C_{1}$ are widely expressed in the $D R G$, including nonpeptidergic nociceptive neurons that are identified via staining with TRITC-labeled IB ${ }_{4}$. Scale bars: $A, B, 200 \mu \mathrm{m} ; C, D, 40 \mu \mathrm{m}$.

overlay at $24 \mathrm{~h}$ with overlay in the basal state in typical examples in Fig. $5 B$; quantification is shown in $D)(F=62.11 ; p<0.001$ over basal state). In contrast, neurites of neurons transduced with AAV-cGASP1 demonstrated only a minor decrease in surface expression of $\mathrm{CB}_{1}$ after a $24 \mathrm{~h}$ exposure to WIN (compare overlay at $24 \mathrm{~h}$ in cGASP1-expressing neurites with overlay in the basal state in typical examples in Fig. 5B), which did not reach statistical significance $(F=2.253 ; p=0.16$ over basal state) (Fig. $5 D)$. These results show that interfering with the GASP1- $\mathrm{CB}_{1}$ interac- tions in primary spinal neurons prevented cannabinoid-induced downregulation of $\mathrm{CB}_{1}$ from the surface of neurites.

\section{Expression of GASP1 in the spinal} sensorimotor circuit processing pain Because nothing has been reported so far on the expression GASP1 protein in the regions of the nervous system that are important in processing pain, we performed immunohistochemistry with an antiGASP1 antibody (Bartlett et al., 2005) on sections of the spinal cord and DRG of mice.

Immunoreactivity for GASP1 was distributed throughout the spinal cord, and a few spinal motor neurons in laminas VIII and IX demonstrated strong immunoreactivity for GASP1 (Fig. 6A, arrow). GASP1 immunoreactivity was most prominent in the spinal dorsal horn, particularly in the superficial spinal laminas, which are important in nociceptive processing (Fig. $6 \mathrm{~A}$, arrowheads). Of note, we observed that immunoreactivity for $\mathrm{CB}_{1}$ is also particularly dense in the superficial lamina I of the spinal dorsal horn (Fig. 6B, arrowhead), consistent with previous reports (Salio et al., 2002). In addition to cell bodies in the superficial laminas, a large part of the GASP1 immunoreactivity was found in the neuropil, reflecting that spinal terminals of nociceptive primary afferent fibers, which densely innervate this region, could harbor cGASP1. Consistent with the above, DRG sections demonstrated vivid GASP1 immunoreactivity in populations of neurons (Fig. 6C). To determine whether $\mathrm{CB}_{1}$ and GASP1 colocalize in DRG neurons, we performed colabeling with a goat anti- $\mathrm{CB}_{1}$ antibody, which does not demonstrate immunoreactivity in $C B_{1}^{-/-}$mice (data not shown). Dual-immunofluorescence analysis revealed a high level of overlap between the expression of $\mathrm{CB}_{1}$ and GASP1 in DRG neurons (Fig. 6C).

To address whether nociceptive neurons express GASP1, we costained sections with $\mathrm{IB}_{4}$-TRITC, which labels the nonpeptidergic population of small-diameter nociceptive neurons (Nagy and Hunt, 1982). Nearly all $\mathrm{IB}_{4}$-TRITC-positive neurons were GASP1 immunoreactive (Fig. 6D, yellow in overlay), but also some other cell types, particularly with large diameters, express GASP1 (Fig. 6D). Several $\mathrm{IB}_{4}$-TRITC-positive neurons also demonstrated anti-CB $\mathrm{CB}_{1}$ immunoreactivity (Fig. 6D), showing that nociceptive neurons can express $\mathrm{CB}_{1}$ and GASP1.

We then addressed whether the expression levels or patterns of GASP 1 are regulated over the periods of sustained exposure to cannabinoids. Mice were repeatedly administered with WIN intraperitoneally ( $2 \mathrm{mg} / \mathrm{kg}$ body weight) over a period of $7 \mathrm{~d}$. Mice 


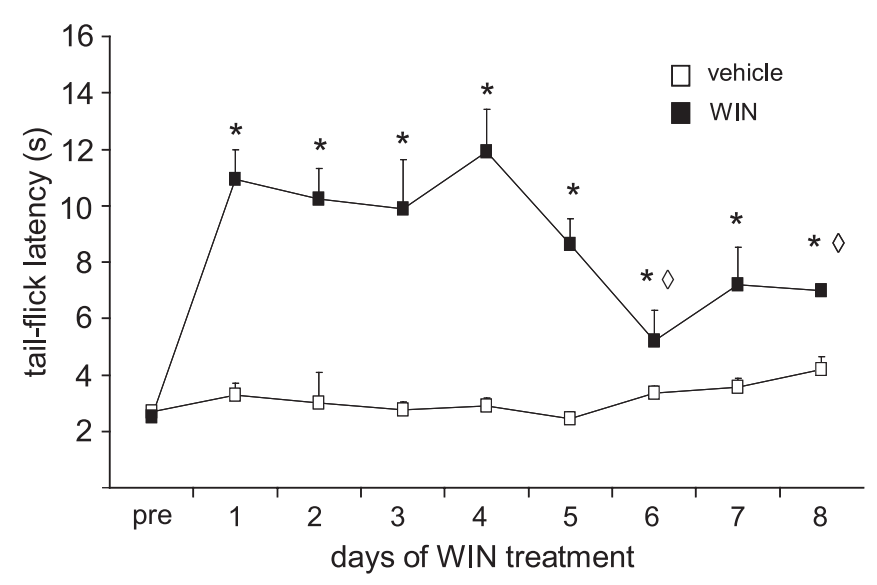

Figure 7. Repetitive treatment with WIN produces analgesic tolerance and $\mathrm{CB}_{1}$ downregulation in the spinal cord in vivo. Intraperitoneal administration of WIN caused a significant increase in tail-flick latency over $8 \mathrm{~d}$ of administration compared with vehicle. $n=4$ or 9 mice per group, respectively. ${ }^{*} p<0.05$ indicates significant difference compared with vehicleinjected mice; ANOVA, post hoc Fisher's test. $\diamond p<0.01$ indicates significant difference compared with WIN-injected mice at day 1; ANOVA, post hoc Fisher's test.

injected with saline in a similar manner served as controls. Immunohistochemistry failed to reveal any obvious changes in the expression of GASP1 in the spinal cords or DRG of mice with long-term cannabinoid treatment over vehicle-treated mice (data not shown). Furthermore, densitometric quantification of GASP1 immunoreactivity over superficial spinal laminas failed to reveal a significant difference between vehicle-treated and WINtreated mice $(26.4 \pm 5$ and $30.9 \pm 4.3$ optical density units, respectively; $F=0.461 ; p=0.516)$.

\section{In vivo analysis of agonist-induced $\mathrm{CB}_{1}$ downregulation and analgesic tolerance}

To study the relevance of our in vitro observations to analgesic tolerance to cannabinoids in vivo, we first established an assay system consisting of two important parameters. First, we analyzed whether repeated systemic administration of WIN leads to analgesic tolerance at the level of the spinal cord in mice, and, second, we assessed whether this process is directly associated with downregulation of $\mathrm{CB}_{1}$ in the spinal cords of the same animals. Because we focused on spinal mechanisms in this study, we chose to analyze the latency of tail withdrawal after application of noxious heat (tail-flick reflex). The tail-flick reflex is a nociceptive withdrawal reflex that is elicited via spinal circuitry and does not require supraspinal pain centers (Kolhekar et al., 1993). Intraperitoneal administration of WIN $(2 \mathrm{mg} / \mathrm{kg})$ acutely produced a more than fourfold increase in the latency of tail-flick to radiant heat (i.e., analgesia) on the first, second, third, and fourth day of WIN administration (Fig. 7$)(F=137.947, p<0.001$ on first day compared with the basal latency; $F=22.648, p=0.003$ on day 2; $F=36.789, p<0.001$ on day $3 ; F=74.05, p<0.001$ on day $4 ; F=$ $44.547, p<0.001$ on day $5 ; F=5.196, p=0.044$ on day $6 ; F=$ $14.366, p=0.003$ on day $7 ; F=16.036, p=0.002$ on day 8 compared with the basal latencies, respectively). Starting from day 5 of WIN administration, WIN-induced analgesia decreased significantly by $>50 \%(F=14.299, p=0.009$ on day 6 compared with analgesia achieved on day $1 ; F=13.728, p=0.010$ on day 8 compared with day 1) (Fig. 7). The spinal cords of chronically WIN- or vehicle-treated mice were then processed for receptor autoradiography, a method that is very sensitive in detecting receptor downregulation in small quantities of tissue. Autoradiog- raphy with ${ }^{3} \mathrm{H}-\mathrm{CP}-55,940$, a high-affinity $\mathrm{CB}_{1}$ agonist (Rubino et al., 2003), revealed a significant decrease in the density of cannabinoid binding sites in the spinal dorsal horn of spinal cords of mice treated chronically with WIN compared with mice that had received the vehicle $\left(13.07 \pm 1.55\right.$ reduction in ${ }^{3} \mathrm{H}-\mathrm{CP}-55940$ binding intensity in the WIN group over vehicle; $F=33.623 ; p<$ $0.001)$. Thus, repeated systemic administration of a cannabinoid produced tolerance to its antinociceptive effects at the level of the spinal cord and led to concurrent downregulation of $\mathrm{CB}_{1}$ in the spinal cord.

\section{Effects of cGASP1 on agonist-induced $\mathrm{CB}_{1}$ downregulation and analgesic tolerance in vivo}

To test the functional significance of the $\mathrm{CB}_{1}-\mathrm{GASP} 1$ interaction in this process in vivo, we sought to perturb this interaction by overexpressing cGASP1 selectively in the superficial spinal laminas of mice. Toward this end, rAAV1/2-cGASP1 virions were injected directly into the spinal parenchyma of adult mice. We previously demonstrated that direct intraparenchymal injection of AAV1/2 virions in the spinal dorsal horn leads to long-lasting expression of desired proteins selectively in the spinal dorsal horn in vivo without producing any toxicity (Tappe et al., 2006). In the present study, intraparenchymal injection of AAV-cGASP1 led to a clearly detectable expression of HA-tagged cGASP1, which was restricted to the spinal dorsal horn, as judged via anti-HA immunohistochemistry (Fig. 8A). A group of control mice injected spinally with rAAV1/2 virions expressing EGFP served as controls (Fig. $8 A$ ). Injected mice did not show any evidence of tissue toxicity or gliosis, as judged via Nissl staining and immunostaining with a neuronal marker (anti-neuronal-specific nuclear protein) or immunostaining with anti-GFAP, respectively, at 2-3 weeks after injection (supplemental Fig. 4, available at www.jneurosci.org as supplemental material).

We then divided cGASP-injected mice and EGFP-injected mice into two groups each: one group was injected with WIN intraperitoneally every day for $14 \mathrm{~d}$, whereas the other (control) group received vehicle injections. Neither EGFP-injected nor cGASP1-injected mice receiving vehicle treatment showed any significant changes in baseline tail-flick latency over the entire period of evaluation. Treatment with WIN produced a significant increase in tail-flick latency in EGFP-injected mice as well as cGASP1-injected mice over the first $2 \mathrm{~d}$ of treatment (Fig. $8 \mathrm{~B}$ ). Although the degree of WIN-induced analgesia was unexpectedly observed to be significantly lower in cGASP1-expressing mice over EGFP-expressing mice on the first day of treatment $(F=$ 9.438; $p=0.01$ ), differences were not apparent at days $2-4$. Importantly, starting with day 6 and up to day 14 of treatment, EGFP-expressing mice demonstrated a progressive decrease in the magnitude of WIN-induced antinociceptive effect on the tailflick reflex, i.e., they developed analgesic tolerance to WIN ( $p<$ 0.001 in all cases; $F$ values were between 25.108 and 440.877 for AAV-EGFP WIN-treated mice compared with vehicle-treated mice from day 1 to 12 ). In striking contrast, cGASP1-expressing mice did not develop any tolerance to WIN and continued to show significant analgesia with WIN over the entire period of analysis (Fig. $8 B)(p<0.001$ in all cases; $F$ values were between 63.758 and 732.55 for AAV-cGASP1 WIN-treated mice compared with vehicle-treated mice from day 1 to $14 ; F=21.83, p<$ 0.001 on day 6 compared with EGFP-expressing mice; $F=$ $45.486, p<0.001$ on day $8 ; F=27.074, p<0.001$ on day $10 ; F=$ $11.927, p<0.001$ on day $12 ; F=100.079, p<0.001$ on day 14 compared with EGFP-expressing mice, respectively).

After the termination of the behavioral analysis, autoradiog- 
A

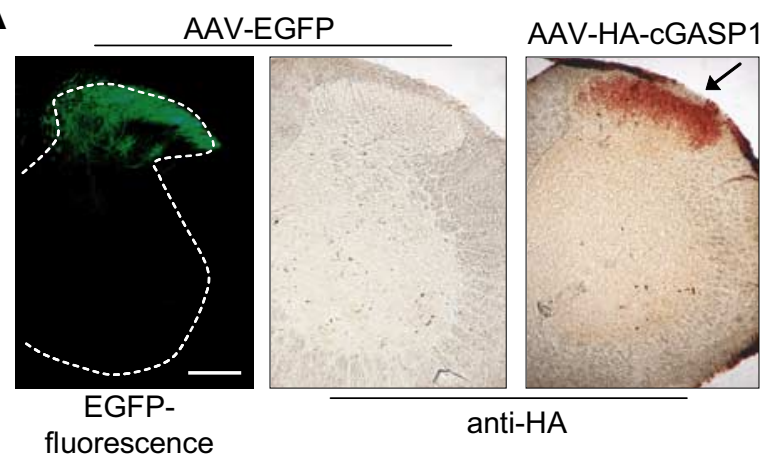

B
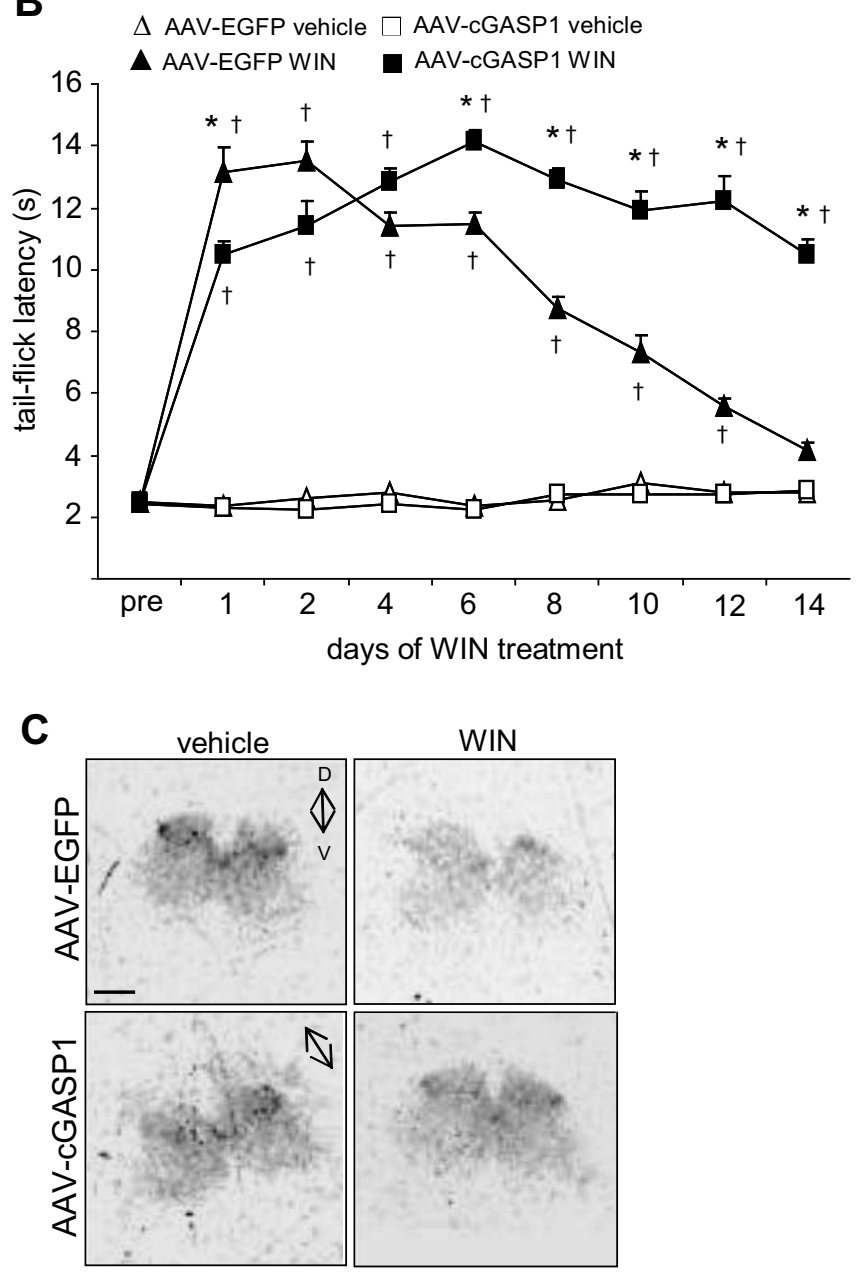

Figure 8. Viral expression of $C \mathrm{GSP} 1$ attenuates tolerance and $\mathrm{CB}_{1}$ downregulation in vivo after repetitive treatment with WIN. AAV virions expressing EGFP or HA-tagged CGASP1 were injected into the spinal parenchyma of mice, and experiments were performed 3 weeks later. $A$, Representative spinal cord sections showing EGFP fluorescence or anti-HA immunoreactivity in the spinal dorsal horn in AAV-EGFP-injected and AAV-HA- CGASP1-injected mice, respectively. $\boldsymbol{B}$, Mice injected intraspinally with AAV-EGFP demonstrated tolerance to the antinociceptive effects of WIN in the tail-flick test, whereas mice injected intraspinally with AAV-HACGASP1 continued to show a WIN-induced increase in tail-flick latency 8-14 d after viral infection. * indicates significant difference compared with AAV-EGFP mice receiving WIN. $†$ indicates significant difference compared with mice receiving vehicle. $C_{\text {, Typical examples of }}$ autoradiographic analysis of $\mathrm{CB}_{1}$ expression with the synthetic $\mathrm{CB}_{1}$ agonist ${ }^{3} \mathrm{H}-\mathrm{CP}-55940$ on spinal dorsal horns of spinal cords from mice treated as shown in $B .{ }^{* \dagger} p<0.001$, ANOVA, post hoc Fisher's test. $n=8$ (AAV- cGASP1 WIN), 6 (AAV-EGFP WIN), 6 (AAV- cGASP1 vehicle), and 4 (AAV-EGFP vehicle) mice. Scale bars: $A, 200 \mu \mathrm{m} ; C, 100 \mu \mathrm{m}$. raphy was performed on spinal cord sections of the tested animals using ${ }^{3} \mathrm{H}-\mathrm{CP}-55,940$. Similar to our results in uninjected mice (Fig. 7, above), EGFP-expressing mice chronically exposed to WIN demonstrated clearly reduced ${ }^{3} \mathrm{H}-\mathrm{CP}-55,940$-binding in the superficial dorsal horn compared with EGFP-expressing mice, which received vehicle treatment $(16.15 \pm 1.48$ reduction in ${ }^{3} \mathrm{H}-\mathrm{CP}-55940$ binding intensity in the WIN group over vehicle) (for a typical example, see Fig. $8 C$ ). In contrast, chronic WIN-induced reduction in spinal ${ }^{3} \mathrm{H}-\mathrm{CP}-55,940$-binding was significantly less pronounced in cGASP1-expressing mice (5.376 \pm 0.845 reduction in ${ }^{3} \mathrm{H}-\mathrm{CP}-55940$ binding intensity in the WIN group over vehicle; $F=32.745, p<0.001$ compared with EGFP-expressing mice).

Together, these data show that downregulation of $\mathrm{CB}_{1}$ as well as analgesic tolerance to repeated, chronic cannabinoid exposure were markedly reduced in mice expressing cGASP1 in the spinal dorsal horn.

\section{Discussion}

We show here that the lysosomal sorting protein, GASP1 interacts with $\mathrm{CB}_{1}$ in the nervous system and mediates downregulation of $\mathrm{CB}_{1}$ during protracted agonist exposure in HEK293 cells, cultured spinal neurons, and spinal cord in vivo. We found that GASP1 is expressed in the spinal cord and dorsal root ganglia in cells that are important in pain processing and cannabinoidinduced analgesia. Importantly, interfering with $\mathrm{CB}_{1}-\mathrm{GASP} 1$ interactions in mouse spinal cord neurons reduced analgesic tolerance to cannabinoids. This study thus provides the insights into protein interactions of $\mathrm{CB}_{1}$ and establishes their central role in $\mathrm{CB}_{1}$ receptor trafficking and analgesic tolerance to cannabinoids in vivo.

A key role for GASP1 in the intracellular trafficking of $\mathrm{CB}_{1}$ Protein-protein interactions constitute one of the most critical determinants of the subcellular localization as well as the signaling mechanisms of several classes of receptors, including GPCRs, ion channels, receptor tyrosine kinases, etc. (Kim and Sheng, 2004; Sexton et al., 2006). We observed that $\mathrm{CB}_{1}$ interacts physically with the $\mathrm{C}$-terminal portion of the lysosomal sorting protein GASP-1. The $\mathrm{CB}_{1}-$ GASP1 interaction did not affect the surface localization of $\mathrm{CB}_{1}$ in naive states, i.e., in the absence of agonists, suggesting that GASP1 does not regulate the initial targeting of newly synthesized $\mathrm{CB}_{1}$ to its site of action in the membrane. Furthermore, the molecular determinants of $\mathrm{CB}_{1}-\mathrm{GASP} 1$ interaction do not lie in those $\mathrm{C}$-terminal amino acids of $\mathrm{CB}_{1}$ that have been implicated in ligand-induced internalization (Hsieh et al., 1999). This is supported by our observation that cGASP1 does not significantly affect ligand-induced internalization but only appears to regulate the later step of internalized $\mathrm{CB}_{1}$ recycling back to the cell surface.

A majority of GPCRs can rapidly recycle to the cell surface after agonist-induced internalization (Tsao and von Zastrow, 2000; von Zastrow, 2003); however, for some GPCRs, lysosomal sorting appears to terminate signaling (Trejo et al., 1998). Consistent with a previous report (Hsieh et al., 1999), we found that $\mathrm{CB}_{1}$ demonstrates both modes of agonist-induced trafficking in HEK293 cells: one that involves a rapid internalization and recycling when receptors are exposed to the agonist over short periods, and another that involves lysosomal targeting and degradation of $\mathrm{CB}_{1}$ during prolonged agonist exposure. We observed that interfering with the GASP1- $\mathrm{CB}_{1}$ interaction selectively affected the fate of internalized receptors after prolonged agonist exposure in HEK293 cells. Because we could coimmunoprecipitate 
GASP1 and CB $_{1}$ from HEK293 cells, spinal neurons, and brain in the absence of exogenously administered $\mathrm{CB}_{1}$ agonists, the interaction between GASP1 and $\mathrm{CB}_{1}$ does not appear to strictly require prolonged agonist-induced activation of $\mathrm{CB}_{1}$. Therefore, the differential fate of internalized receptors after short or prolonged exposure to the agonist is likely not determined by differential coupling to GASP1. It is possible that a prolonged exposure, but not a short-term exposure, to the agonist places the $\mathrm{CB}_{1}$-GASP1 complex in a conformation that permits sorting of $\mathrm{CB}_{1}$ into lysosomes.

\section{GASP1 determines the fate of native $\mathrm{CB}_{1}$ in neurons ex vivo and in vivo}

A critical question is whether the above scenario for $\mathrm{CB}_{1}$ expressed heterologously in HEK293 cells is relevant to $\mathrm{CB}_{1}$ natively expressed in neurons. Consistent with a previous report on cultured hippocampal neurons (Coutts et al., 2001), we observed in primary cultures of spinal neurons that a downregulation of native $\mathrm{CB}_{1}$ from the dendritic surface required agonist exposure over much longer periods to be evident than in HEK293 cells. It is possible that shorter periods of exposure leads to internalization and rapid recycling that is below the sensitivity limits of our method of detection. Importantly, and entirely consistent with

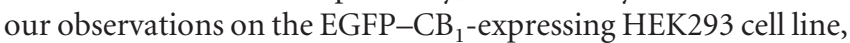
downregulation of $\mathrm{CB}_{1}$ in neurites of spinal neurons during prolonged agonist exposure was significantly attenuated during disruption of the $\mathrm{CB}_{1}-\mathrm{GASP} 1$ association. Thus, GASP1 is a key mediator of the $\mathrm{CB}_{1}$ degradation after agonist exposure in neurons.

Using receptor autoradiography, we found that chronic treatment with a cannabinoid indeed downregulates binding sites for $\mathrm{CB}_{1}$ in the spinal cord of mice and that the $\mathrm{CB}_{1}-\mathrm{GASP} 1$ interaction is required for this process. Neither the level of $\mathrm{CB}_{1}$ expression on the surface of spinal neurites nor the magnitude of ligand binding in the spinal cord was affected by cGASP1 in the absence of the agonist. This suggests that the GASP1- $\mathrm{CB}_{1}$ interaction does not affect the expression of endogenous $\mathrm{CB}_{1}$ in neurons per se but selectively regulates the surface recovery of $\mathrm{CB}_{1}$ after agonist exposure. Together, our comprehensive analyses from heterologous, ex vivo, and in vivo neuronal systems show that GASP1 mediates degradation and downregulation of $\mathrm{CB}_{1}$ during prolonged or repetitive treatment with cannabinoids.

\section{Functional relevance of $\mathrm{CB}_{1}-\mathrm{GASP} 1$ interaction to analgesic tolerance to cannabinoids}

Studies that test the applicability of results derived from trafficking experiments in vitro to drug tolerance phenomena in animal models and clinical settings are very scarce (He et al., 2002; Bartlett et al., 2005). Here, we directly explored the significance of the $\mathrm{CB}_{1}-\mathrm{GASP} 1$ interaction to the tolerance that develops to the analgesic effects of cannabinoids during repeated administration to mice. The overexpression of cGASP1 in the superficial laminas processing nociceptive inputs was sufficient to prevent tolerance that developed toward the spinal antinociceptive effects of a cannabinoid during systemic administration over 6-14 d. cGASP1 also antagonized downregulation of $\mathrm{CB}_{1}$ caused by chronic cannabinoid administration. These results thus validate the functional significance of the $\mathrm{CB}_{1}-\mathrm{GASP} 1$ interaction in the intact nervous system and provide a crucial link between receptor downregulation in vitro and in vivo with the complex phenomenon of drug tolerance in an animal. However, it is important to note that the striking effect of spinally expressed cGASP on analgesic tolerance to cannabinoid treatment could be detected be- cause we chose a nociceptive test, the tail-flick reflex, which is mediated by the spinal nociceptive circuitry. Because cannabinoids induce analgesia by activating receptors at multiple avenues in the pain pathway, to clinically exploit $\mathrm{CB}_{1}-\mathrm{GASP} 1$ interaction, it will be important to target various loci in the nervous system and not the spinal cord alone.

Using Northern blotting and in situ hybridization, Simonin et al. (2004) recently described the expression of GASP1 mRNA in a few organs. However, the expression of GASP1 in regions important in pain processing was not characterized in detail. Moreover, nothing has been reported so far on the expression GASP1 protein in nociceptive pathways. We observed strong immunoreactivity for GASP1 in neurons of the DRG, including nonpeptidergic nociceptors, which also express $\mathrm{CB}_{1}$. In the spinal cord, GASP1 immunoreactivity was most abundant in the superficial laminas, consistent with a high density of $\mathrm{CB}_{1}$ in the dorsal horn, which was revealed by binding sites for ${ }^{3} \mathrm{H}-\mathrm{CP}-55,940$. We did not detect any obvious changes in the expression levels of GASP1 protein in the spinal dorsal horn during chronic exposure to cannabinoids in any of the mice tested. However, it might be interesting to address whether a differential constitutive expression of GASP1 correlates with the degree to which analgesic tolerance develops in individual subjects, which might clarify the clinical observation that some patients are more predisposed than others to develop analgesic tolerance. Recent studies have suggested that the activation of protein kinase A (PKA) and Src tyrosine kinase, but not of protein kinase $C$ or protein kinase $G$, can reverse tolerance to some of the biological effects of the natural cannabinoid $\Delta$ 9-tetra hydro cannabinol, although cannabinoid-induced analgesia was not tested (Lee et al., 2003; Bass et al., 2004). It will be interesting to see whether PKA and Src-induced effects involve modulation of GASP1 function.

Tolerance limits the utility of cannabinoids as well as opioids in long-term clinical management of chronic pain disorders (Herning et al., 1981; Pertwee, 1991; Jasinski, 1997; Jage, 2005; Lichtman and Martin, 2005). Because we observed a requirement for GASP1- $\mathrm{CB}_{1}$ interactions for the development of tolerance toward the spinal antinociceptive effects of cannabinoids, the disruption of the $\mathrm{CB}_{1}-\mathrm{GASP} 1$ interaction may provide a basis for improving the clinical utility of cannabinoids. In this regard, the recombinant AAV vector that we used to selectively overexpress cGASP1 in the spinal dorsal horn is optimized to provide a high efficiency of transduction, stable expression in the CNS over months, tropism for neurons, and a lack of an immune response and toxicity (Mastakov et al., 2002; During et al., 2003). Despite this, cGASP may not be an optimal tool because it would target interactions of GASP1 with several other GPCRs (Heydorn et al., 2004; Simonin et al., 2004; Bartlett et al., 2005), which may be important in physiological pain and other biological functions. Rather, targeting regions of $\mathrm{CB}_{1}$ that physically interact with GASP1 via small molecules or decoy peptides may enable selectively inhibiting GASP1-mediated degradation of $\mathrm{CB}_{1}$ and thereby help to improve the magnitude and duration of cannabinoid-induced analgesia in chronic pain states.

In summary, this study establishes a crucial functional link between lysosomal sorting of $\mathrm{CB}_{1}$ and tolerance to cannabinoidinduced analgesia and clarifies the molecular mechanisms underlying these biologically and clinically relevant phenomena.

\section{References}

Bartlett SE, Enquist J, Hopf FW, Lee JH, Gladher F, Kharazia V, Waldhoer M, Mailliard WS, Armstrong R, Bonci A, Whistler JL (2005) Dopamine responsiveness is regulated by targeted sorting of D2 receptors. Proc Natl Acad Sci USA 102:11521-11526. 
Bass CE, Welch SP, Martin BR (2004) Reversal of delta 9-tetrahydrocannabinol-induced tolerance by specific kinase inhibitors. Eur J Pharmacol 496:99-108.

Calignano A, La Rana G, Giuffrida A, Piomelli D (1998) Control of pain initiation by endogenous cannabinoids. Nature 394:277-281.

Coutts AA, Anavi-Goffer S, Ross RA, MacEwan DJ, Mackie K, Pertwee RG, Irving AJ (2001) Agonist-induced internalization and trafficking of cannabinoid $\mathrm{CB}_{1}$ receptors in hippocampal neurons. J Neurosci 21:2425-2433.

De Vry J, Jentzsch KR, Kuhl E, Eckel G (2004) Behavioral effects of cannabinoids show differential sensitivity to cannabinoid receptor blockade and tolerance development. Behav Pharmacol 15:1-12.

Dreyer J, Hirlinger D, Muller-Esterl W, Oess S, Kuner R (2003) Spinal upregulation of the nitric oxide synthase-interacting protein NOSIP in a rat model of inflammatory pain. Neurosci Lett 350:13-16.

During MJ, Young D, Baer K, Lawlor P, Klugmann M (2003) Development and optimization of adeno-associated virus vector transfer into the central nervous system. Methods Mol Med 76:221-236.

Gonzalez S, Cebeira M, Fernandez-Ruiz J (2005) Cannabinoid tolerance and dependence: a review of studies in laboratory animals. Pharmacol Biochem Behav 81:300-318.

Grimm D, Kay MA, Kleinschmidt JA (2003) Helper virus-free, optically controllable, and two-plasmid-based production of adeno-associated virus vectors of serotypes 1 to 6 . Mol Ther 7:839-850.

Hartmann B, Ahmadi S, Heppenstall PA, Lewin GR, Schott C, Borchardt T, Seeburg PH, Zeilhofer HU, Sprengel R, Kuner R (2004) The AMPA receptor subunits GluR-A and GluR-B reciprocally modulate spinal synaptic plasticity and inflammatory pain. Neuron 44:637-650.

He L, Fong J, von Zastrow M, Whistler JL (2002) Regulation of opioid receptor trafficking and morphine tolerance by receptor oligomerization. Cell 108:271-282.

Herning RI, Jones RT, Benowitz NL (1981) Clinical relevance of cannabis tolerance and dependence. J Clin Pharmacol 8-9:143S-152S.

Heydorn A, Sondergaard BP, Ersboll B, Holst B, Nielsen FC, Haft CR, Whistler J, Schwartz TW (2004) A library of 7TM receptor C-terminal tails. Interactions with the proposed post-endocytic sorting proteins ERMbinding phosphoprotein 50 (EBP50), N-ethylmaleimide-sensitive factor (NSF), sorting nexin 1 (SNX1), and G-protein-coupled receptorassociated sorting protein (GASP). J Biol Chem 279:54291-54303.

Hsieh C, Brown S, Derleth C, Mackie K (1999) Internalization and recycling of the CB1 cannabinoid receptor. J Neurochem 73:493-501.

Iverson L (2003) Cannabis and the brain. Brain 126:1252-1270.

Jage J (2005) Opioid tolerance and dependence: do they matter? Eur J Pain 9:157-162.

Jasinski DR (1997) Tolerance and dependence to opiates. Acta Anaesthesiol Scand 41:184-186.

Jin W, Brown S, Roche JP, Hsieh C, Celver JP, Kovoor A, Chavkin C, Mackie $\mathrm{K}$ (1999) Distinct domains of the $\mathrm{CB}_{1}$ cannabinoid receptor mediate desensitization and internalization. J Neurosci 19:3773-3780.

Kim E, Sheng M (2004) PDZ domain proteins of synapses. Nat Rev Neurosci 5:771-781.

Kolhekar R, Meller ST, Gebhart GF (1993) Characterization of the role of spinal $N$-methyl-D-aspartate receptors in thermal nociception in the rat. Neuroscience 57:385-395.

Lee MC, Smith FL, Stevens DL, Welch SP (2003) The role of several kinases in mice tolerant to delta 9-tetrahydrocannabinol. J Pharmacol Exp Ther 305:593-599.

Leterrier C, Bonnard D, Carrel D, Rossier J, Lenkei Z (2004) Constitutive endocytic cycle of the $\mathrm{CB1}$ cannabinoid receptor. J Biol Chem 279:36013-36021.

Leterrier C, Laine J, Darmon M, Boudin H, Rossier J, Lenkei Z (2006) Constitutive activation drives compartment-selective endocytosis and axonal targeting of type 1 cannabinoid receptors. J Neurosci 26:3141-3153.
Lichtman AH, Martin BR (2005) Cannabinoid tolerance and dependence. Handb Exp Pharmacol 168:691-717.

Mackie K (2006) Cannabinoid receptors as therapeutic targets. Annu Rev Pharmacol Toxicol 46:101-122.

Marsicano G, Lutz B (2006) Neuromodulatory functions of the endocannabinoid system. J Endocrinol Invest 29:27-46.

Martin BR, Sim-Selley LJ, Selley DE (2004) Signaling pathways involved in the development of cannabinoid tolerance. Trends Pharmacol Sci 25:325-330.

Mastakov MY, Baer K, Symes CW, Leichtlein CB, Kotin RM, During MJ (2002) Immunological aspects of recombinant adeno-associated virus delivery to the mammalian brain. J Virol 76:8446-8454.

McDonald NA, Henstridge CM, Connolly CN, Irving AJ (2007) An essential role for constitutive endocytosis, but not activity, in the axonal targeting of the CB1 cannabinoid receptor. Mol Pharmacol, in press.

Nagy JI, Hunt SP (1982) Fluoride-resistant acid phosphatase-containing neurones in dorsal root ganglia are separate from those containing substance P or somatostatin. Neuroscience 7:89-97.

Pertwee RG (1991) Tolerance to and dependence on psychotropic cannabinoids. In: The biological bases of drug tolerance and dependence (Pratt J, ed), pp 231-263. London: Academic.

Rice AS (2001) Cannabinoids and pain. Curr Opin Investig Drugs 2:399-414

Rubino T, Vigano D, Massi P, Parolaro D (2003) Cellular mechanisms of Delta 9-tetrahydrocannabinol behavioural sensitization. Eur J Neurosci 17:325-330.

Rubino T, Forlani G, Vigano D, Zippel R, Parolaio D (2005) Ras/ERK signalling in cannabinoid tolerance: from behaviour to cellular aspects. J Neurochem 93:984-991.

Salio C, Fischer J, Franzoni MF, Conrath M (2002) Pre- and postsynaptic localizations of the CB1 cannabinoid receptor in the dorsal horn of the rat spinal cord. Neuroscience 110:755-764.

Sexton PM, Morfis M, Tilakaratne N, Hay DL, Udawela M, Christopoulos G, Christopoulos A (2006) Complexing receptor pharmacology: modulation of family B G protein-coupled receptor function by RAMPs. Ann NY Acad Sci 1070:90-104.

Shire D, Carillon C, Kaghad M, Calandra B, Rinaldi-Carmona M, Le Fur G, Caput D, Ferrara P (1995) An amino-terminal variant of the central cannabinoid receptor resulting from alternative splicing. J Biol Chem 270:3726-3731.

Simonin F, Karcher P, Boeuf JJ, Matifas A, Kieffer BL (2004) Identification of a novel family of $\mathrm{G}$ protein-coupled receptor associated sorting proteins. J Neurochem 89:766-775.

Swiercz JM, Kuner R, Offermanns S (2004) Plexin-B1/RhoGEF-mediated RhoA activation involves the receptor tyrosine kinase ErbB-2. J Cell Biol 165:869-880.

Tappe A, Klugmann M, Luo C, Hirlinger D, Agarwal N, Benrath J, Ehrengruber MU, During MJ, Kuner R (2006) Synaptic scaffolding protein Homerla protects against chronic inflammatory pain. Nat Med 12:677-681.

Trejo J, Hammes SR, Coughlin SR (1998) Termination of signaling by protease-activated receptor-1 is linked to lysosomal sorting. Proc Natl Acad Sci USA 95:13698-13702.

Tsao P, von Zastrow M (2000) Downregulation of G protein-coupled receptors. Curr Opin Neurobiol 10:365-369.

von Zastrow M (2003) Mechanisms regulating membrane trafficking of G protein-coupled receptors in the endocytic pathway. Life Sci 74:217-224.

Walker JM, Hohmann AG (2005) Cannabinoid mechanisms of pain suppression. Handb Exp Pharmacol 168:509-554.

Whistler JL, Enquist J, Marley A, Fong J, Gladher F, Tsuruda P, Murray SR, von Zastrow M (2002) Modulation of postendocytic sorting of G protein-coupled receptors. Science 297:615-620.

Wimmer VC, Nevian T, Kuner T (2004) Targeted in vivo expression of proteins in the calyx of Held. Pflügers Arch 449:319-333. 